\title{
Factors that impact West Virginia Head Start parental involvement in early literacy
}

Arlene Midget Clausell

West Virginia University

Follow this and additional works at: https://researchrepository.wvu.edu/etd

\section{Recommended Citation}

Clausell, Arlene Midget, "Factors that impact West Virginia Head Start parental involvement in early literacy" (2010). Graduate Theses, Dissertations, and Problem Reports. 2943.

https://researchrepository.wvu.edu/etd/2943

This Dissertation is protected by copyright and/or related rights. It has been brought to you by the The Research Repository @ WVU with permission from the rights-holder(s). You are free to use this Dissertation in any way that is permitted by the copyright and related rights legislation that applies to your use. For other uses you must obtain permission from the rights-holder(s) directly, unless additional rights are indicated by a Creative Commons license in the record and/ or on the work itself. This Dissertation has been accepted for inclusion in WVU Graduate Theses, Dissertations, and Problem Reports collection by an authorized administrator of The Research Repository @ WVU.

For more information, please contact researchrepository@mail.wvu.edu. 


\title{
FACTORS THAT IMPACT WEST VIRGINIA HEAD START \\ PARENTAL INVOLVEMENT IN EARLY LITERACY
}

\author{
Arlene Midget Clausell
}

\author{
Dissertation submitted to the \\ College of Human Resources and Education \\ at West Virginia University \\ in partial fulfillment of the requirements \\ for the degree of \\ Doctor of Education \\ in \\ Curriculum and Instruction
}

\author{
Joy Faini Saab, Ed.D, Chair \\ Steve Rinehart, Ph.D. \\ Neal Shambaugh, Ph.D. \\ David Callejo, Ed.D. \\ Christina Wilson, Ph.D. \\ Department of Curriculum and Instruction
}

Morgantown, West Virginia

2010

Key words: Head Start, early literacy skill, parental involvement, West Virginia, home literacy survey, home literacy

Copyright 2010 Arlene Midget Clausell 


\section{Abstract \\ Factors that Impact West Virginia Head Start \\ Parental Involvement in Early Literacy}

\section{Arlene Midget Clausell}

The research problem is: Many parents are not involved in their children's early literacy education. Some Head Start parents experience issues that keep them from teaching their children early literacy skills. The research questions were: What are the factors for parental involvement in the support of early literacy skill development for their children? What do parents in Head Start do to support early literacy development in their children? What are the barriers in how parents support literacy development for their children? This research included 392 parents from Head Start centers in West Virginia. Eleven parents participated in focus groups and 381 completed home literacy surveys. The major issues identified by the parents were work, childcare, time, money, too busy, and transportation. Initially, four questions were constructed to give to 11 parents in a focus group. The questions were about the parents' early literacy skills and understanding of parental involvement. The home literacy survey is divided into three parts. The SPSS software was used to tabulate the results Marion's (2004) study found "The experiences of a child during their first year of life are capable of changing the way a child turns out" (p. 17). Parents should contact Head Start officials when they can not attend meeting and explain why. Head Start center staff should make sure the families understand all the opportunities that are available to them. 


\section{Acknowledgements}

I wish to thank the following: God, my parents James and Ollie Midget, my husband Paul L.

Clausell, my sons Christopher and Eric Clausell, Mrs. Kathy Fletcher, Dr. Elizabeth Dooley, and my committee: Dr. Steve Rinehart, Dr. Neal Shambaugh, Dr. David Callejo, Dr. Christina Wilson, my chair Dr. joy Faini Saab and everyone else who helped me. 


\section{Table of Contents}

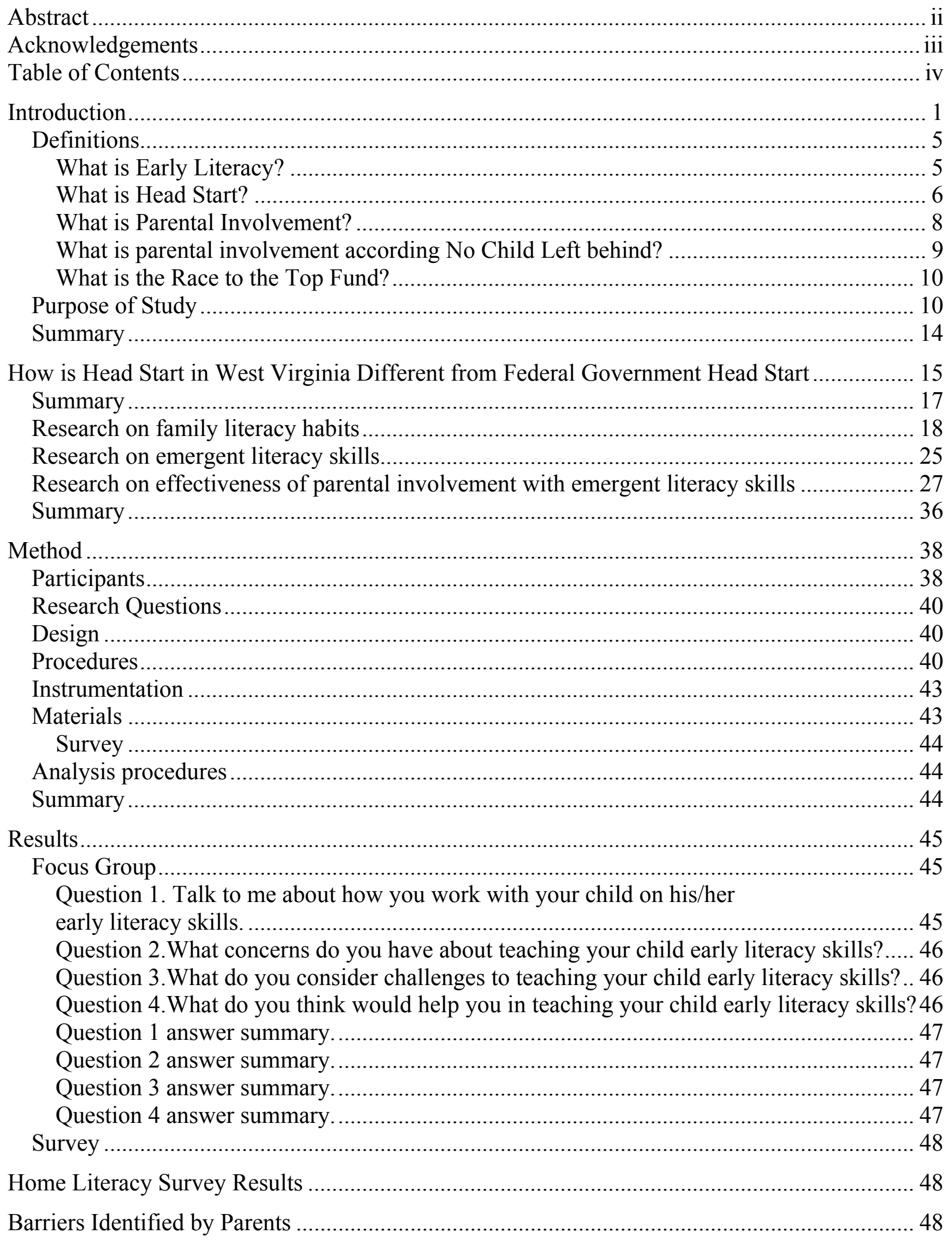




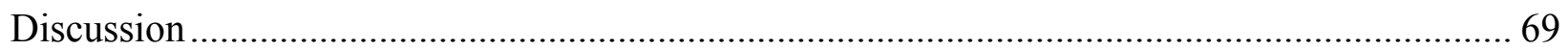

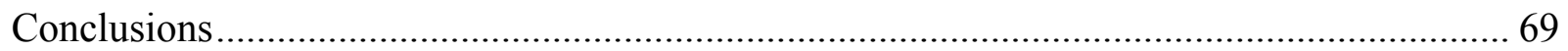

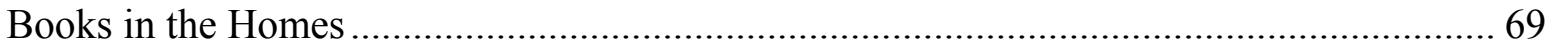

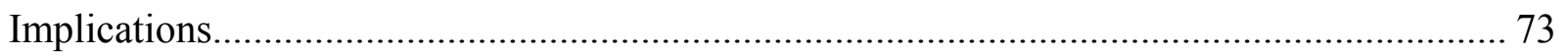

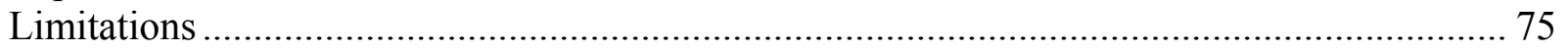

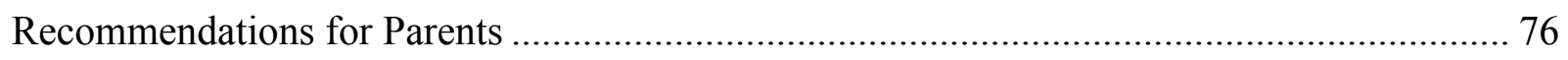

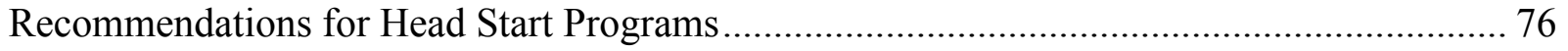

Recommendations for Further Research.................................................................... 78

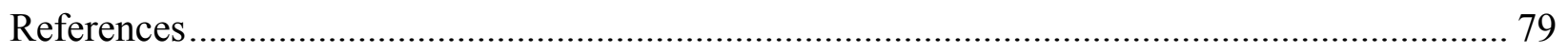

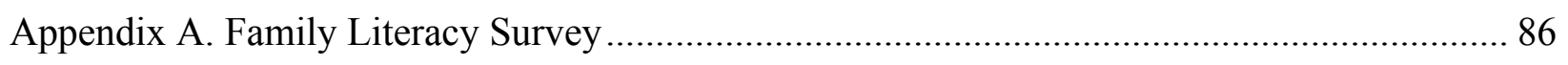

Appendix B. Head Start Program Performance Standards ...................................................... 94

Appendix C. Cover Letter for Survey ............................................................................ 105

Appendix D. Cover Letter for Focus Group ........................................................................ 107 


\section{List of Tables}

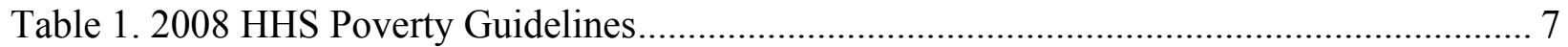

Table 2. Northern Panhandle West Virginia Head Start......................................................... 38

Table 3. North Central West Virginia Head Start............................................................... 39

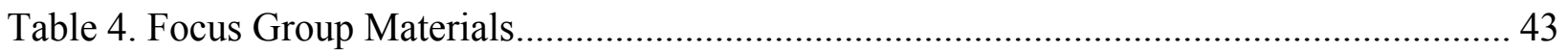

Table 5. Summaries of Findings: Most Influential .............................................................. 48

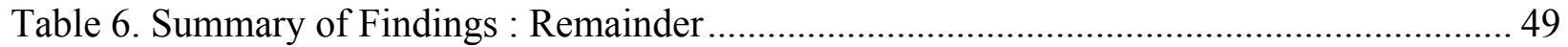

\section{List of Figures}

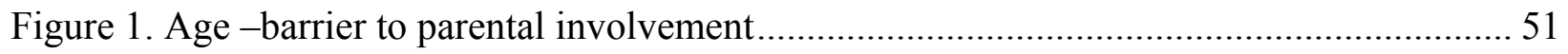

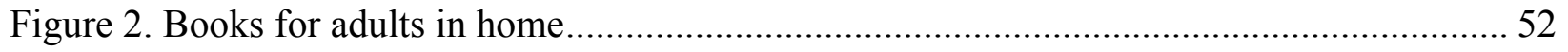

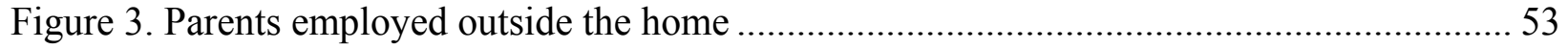

Figure 4. Completed education level of parents taking survey ............................................. 54

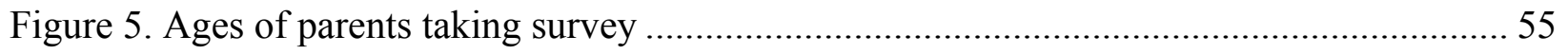

Figure 6. Gender of parents taking the survey .............................................................. 56

Figure 7. Parents whose moms did teach them to read...................................................... 57

Figure 8. Childcare -- barrier to parental involvement ..................................................... 58

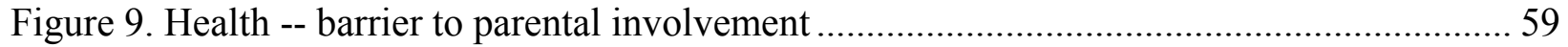

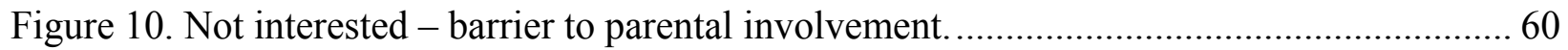

Figure 11. Location--barrier to parental involvement................................................... 61

Figure 12. Lack of materials-- barrier to parental involvement............................................ 62

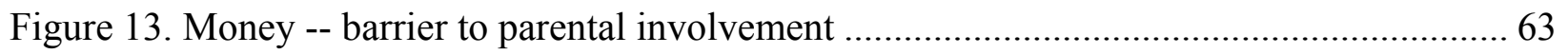

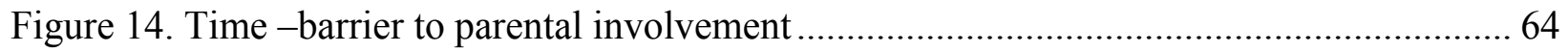

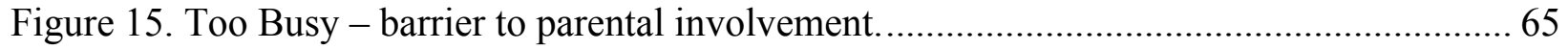

Figure 16. Transportation - barrier to parental involvement ................................................ 66

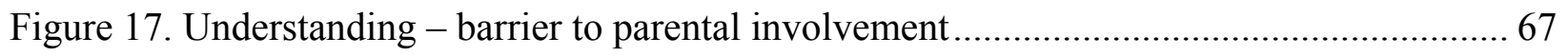

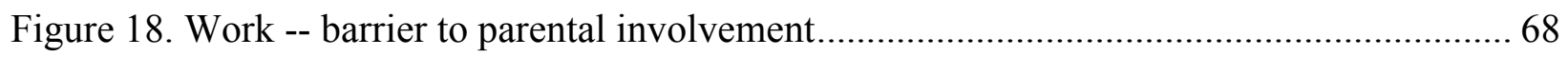




\section{Factors That Impact West Virginia Head Start Parental Involvement In Early Literacy}

Everyone needs a good education. Having a good education equips them with the necessary tools to be successful. Education changes the way people do things. It enhances the opportunities for each child.

Parental Involvement cannot be a one-time thing. It has to be ongoing. Parents must be involved from life to death with their children's lives. As the children grow older, the parents' responsibilities change. When the children are adults, their parents serve in a different capacity. Teale talked about early literacy.

When the families are trained in successful home literacy skills, the children develop positive attitudes about learning.

In a historical treatment of discussions about early literacy instruction, Teale (2000) wrote "Learning to read and write begins very early in life for virtually all children in a literate society, rather than at age 5 or $6 "$ (p. 5). Children need to be exposed to early emergent literacy skills early in their lives. McGee and Richgels researched and authored a book, which supported early literacy skills and felt that they are critical and serve as the foundation for children's success in learning to read and write. According to McGee (2003), “Children's literacy experiences prior to first grade are critical for their success in learning to read and write. During these years they must acquire foundational understanding about the uses of reading and writing." (p. 1)

The Committee on the Prevention of Reading Difficulties (1998) reported in Preventing Reading Difficulties in Young Children "Learning to read begins long before the school years, as biological, cognitive, and social precursors are put into place" (p. 43). Children need to feel confident. They need to know that they are capable and expected to do great things. In Democracy and Education, Dewey (1916) wrote “ Power to grow depends upon need for others 
and plasticity. Both these conditions are at their height in childhood and youth. Plasticity or the power to learn from experience means the formation of habits. Habit gives control over the environment, power to utilize it for human purpose" (p. 52). Habits help children develop important early literacy skills. As the children develop more habits their skills become complex. The children are building on their foundation of habits. Children need these habits and skills to move to the next level of learning.

The Children's Defense Fund Committee wrote “ Widespread research shows that success in school is often related to early education experiences that occur before a child enters kindergarten.” (Children's Defense Fund, 2000, p. 68) Several researchers support this stance.

Marie Clay (1983) wrote in Reading Recovery "The first essential step towards reading and writing success is to have good preschool experiences available to all children. This would ensure that almost all children entered school easily able to converse with others about the world and how they understood it" (p. 1).

The children have their own responsibilities, which are their own families. Parent involvement serves as a base to guide and counsel children through life. Parents are paying attention to their children. Children need and get their parents attention. It can be positive or negative. That is determined by the kind of involvement that parents are willing to demonstrate towards their children. Parental involvement is desired of all parents. Factors such as race, age, and economical status do not excuse any group of parents from being involved. Parents should not be excused from parental involvement because of past histories of various groups, which they may represent. Honig (1999) in her study of parent involvement in the early years wrote "a caring parent committed to children's secure well-being is a person every society should honor or cherish. Quality parenting is the secret indispensable ingredient to provide the inner core of self-love and self-esteem that sustains each growing child and permits that child in turn to care 
for others in ways that sustain family and community" (p. 4). When children have strong selfesteem, they are more likely to master early literacy skills. They enter the school ready to learn and to move to the next level in the learning process. The transitions are smooth because of the children's attitudes toward learning. They are ready to learn. Sometimes the transitions are not smooth and children are not ready to learn because they do not have the foundation from home. They have not been taught any early literacy skills. If they have not been taught early literacy skills their experiences in school will be negative.

VanderStaay's study looked at the effects of low performance in school. His study supported the idea that children need to have positive experiences in school instead of negative experiences. The results from the VanderStaay (2006) study showed that negative experiences in school were connected with delinquent behaviors. When parents are involved positively the children work towards excelling in school, and they can develop self-confidence. VanderStaay(2006) Every human being, especially children, needs self-esteem. Children need to know that there are things that they can do right. Education does not start at school. It starts at home with early literacy skills and home literacy. Parents need to teach their children early literacy skills which support their learning and provide them with a sense of self esteem. If children enter school as a blank slate and their fellow classmates enter with many early literacy skills, the blank slate children experience a sense of being lost. As they progress through school, their sense of lost turns into frustration. The desire to learn slowly disappears. The children who are falling behind find ways to vent their frustration. This venting causes problems for them. They fall behind even more and learn even less. They slowly fall into a black hole of slow learners. If they do not vent their hostilities, they become invisible children. They too fall into the black hole of slow learners. Both groups end up in special education. They become the truant students who stop coming to school and look forward to dropping out of school because 
there is nothing positive for them in the educational institution. Some end up in jail because they are looking for ways to gain someone's attention. They want their parents involved. If the parents are coming to jail or the principal's office the children are getting their parent's attention. The parents are involved. There is no way for them to catch up with their classmates. These children do not have the foundation that is needed for success. Some children never learn to read and write.

McGee's (2003) study supported early literacy skills and felt that they are critical and serve as the foundation for children's success in learning to read and write (p. 9). When children enter school able to read and write, they are ready to learn. They understand what school is about. They have the tools to express themselves. They can communicate with each other, family members, and their teachers. They understand what is required of them. Children understand that going to school is part of the learning process. They can do the following early literacy skills: identify the letters of the alphabet, know the parts of a book, can listen, they start reading books, can talk about what they have learned from hearing a story read or told to them, and they can write.

Parents are the children's first teachers. The behaviors that parents exhibit at home inform the children of the importance of education. If they see their parents reading at home, they know that it is important to learn to read. If they see their parents writing at home, they know that writing is important. When children see their parents using literacy skills, they want to use literary skills. It is very important for parents to be involved in their children's education as they move through the educational system and before they enter the educational system. Parents teach their children to talk, walk, and a collection of critical skills for life. Teaching their children early literacy skills can be a natural progression. The children work with their parents and discover early literacy skills in a one on one environment. The children are introduced to 
new skills as they master their old skills. Their learning is not forced and it gets more complex as the children display behaviors that show that they are ready for more challenging skills. The parents are aware of where their children are in their skills development. They know their children. At the same time, the children are developing strong self-esteem and self-confidence. They are having positive experiences. The relationships between the children and their parents are growing and they are bonding.

Bowman (2006) conducted a study and found "Children from low-income families and children from diverse ethnic, cultural, and language backgrounds are at high risk of school failure. They fail because [educators] do not provide them with the kind of educational support that they need" (p. 54) .

Many behaviors that children learn from their parents are those that the parents model. Parents do not have to give instructions. If the children see their parents reading magazines, they will read or imitate reading magazines. If their parents communicate with each other and the children, they will communicate with their parents and others. If the children see their parents drinking alcohol, they will think that it is okay to drink alcohol. If their parents are very happy people, the children will be happy people. If parents say that education is important and model that attitude in their behaviors in regard to education, their children will believe that education is important and work to be successful in school. Their success is dependent on the foundation that has been built at home through early literacy skills and growing up in a literate home environment.

Early literacy skill training is important for children before they enter the school for kindergarten. Parental involvement can provide that training for the children.

\section{Definitions}

What is Early Literacy? According to Strickland (2000), 
- Learning to read and write begins very early in life for virtually all children in a literate society rather than at age 5 or 6 .

- Literacy development is the more appropriate way to describe what was called reading readiness: the child develops not merely in reading, but as a writer/reader. Reading, writing, and oral language develop concurrently and interrelatedly rather than sequentially.

- Literacy develops within the framework of real-life activities in order to "get things done". Therefore, the meaningful or purposeful bases of early literacy are a critical part of learning to read and write and must be emphasized in curriculum.

- Children learn written language through active engagement with their world not merely by completing workbook activities or other types of academic exercises.

- A much broader range of knowledge, dispositions, and strategies is involved in young children's becoming literate than is emphasized in reading and readiness programs.

- Although children's acquisition of literacy can be described in general stages, children become literate at different rates and take a variety of paths to conventional reading and writing. Attempts to "scope and sequence" instruction, such as those typical of reading readiness programs, do not take this developmental variation into account. (p.5)

What is Head Start? In 1965 Head Start was started by the of the United States Department of Health and Human services it is a program which focuses on assisting children from low income families. Head Start was created in 1965 and is the longest running program to stop the cycle of poverty in the United States. It provides comprehensive education, health, nutrition, and parent involvement services to low-income children and their families. As of late 2005, more 
than 22 million pre-school aged children have participated in Head Start. The \$6.8+ billion dollar budget for 2005 provided services to more than 905,000 children, 57\% of whom were four years old or older, and $43 \%$ three years old or younger. Services were provided by 1,604 different programs operating more than 48,000 classrooms scattered across every state (and nearly every county) at an average cost of $\$ 7,222$ per child. The paid staff of nearly 212,000 people is dwarfed by an army of volunteers six times as large.

Eligibility for Head Start services is largely income-based (100\% of the federal poverty level), though each locally-operated program includes other eligibility criteria such as disabilities and services to other family members. Up to $10 \%$ of any funded program's enrollment can be from over-income families or families experiencing emergency situations, but with the latest Head Start Act there was a provision to offer an option to serve children from 100 to $130 \%$ of the federal poverty guidelines. All programs are required to provide full services to children with disabilities $(10 \%$ of their total enrollment). Signed by President Bush December 12, 2007, "Improving Head Start for School Readiness Act of 2007’'.

Table 1

2008 HHS Poverty Guidelines

Chart used by Head Start to determine who qualifies for the program.

\begin{tabular}{cccc}
\hline $\begin{array}{c}\text { Persons } \\
\text { in Family or Household }\end{array}$ & $\begin{array}{c}\text { 48 Contiguous } \\
\text { States and D.C. }\end{array}$ & Alaska & Hawaii \\
\hline 1 & $\$ 10,400$ & $\$ 13,000$ & $\$ 11,960$ \\
2 & 14,000 & 17,500 & 16,100 \\
3 & 17,600 & 22,000 & 20,240 \\
4 & 21,200 & 26,500 & 24,380 \\
5 & 24,800 & 31,000 & 28,520 \\
6 & 28,400 & 35,500 & 32,660
\end{tabular}


Table 1 continued

\begin{tabular}{cccc}
\hline $\begin{array}{c}\text { Persons } \\
\text { in Family or Household }\end{array}$ & $\begin{array}{c}\text { 48 Contiguous } \\
\text { States and D.C. }\end{array}$ & Alaska & Hawaii \\
\hline 7 & $\$ 32,000$ & $\$ 40,000$ & $\$ 36,800$ \\
8 & 35,600 & 44,500 & 40,940 \\
$\begin{array}{l}\text { For each additional } \\
\text { person, add }\end{array}$ & 3,600 & 4,500 & 4,140 \\
\hline
\end{tabular}

SOURCE: Federal Register, Vol. 73, No. 15, January 23, 2008, pp. 3971-3972

Head Start parental involvement services address training, parenting, socialization and home life. The training is done through home visits and teaching sessions. Some of the teaching is one on one. The parents help out in the classroom. They assist children who are having difficult with activities. They help serve meals and snacks. They observe the children and the teacher working together. They watch the teachers and aides read to the children. They read to the children. They play educational games with the children.

What is parental involvement? Epstein (2001) has develop an excellent model for parental involvement which is very clear :

- Parenting. Assist families with parenting skills, family support, understanding child and adolescent development, and setting home conditions to support learning at each age and grade level. Assist schools in understanding families' backgrounds, cultures, and goals for children.

- Communicating. Communicate with families about school programs and student progress. Create two-way communication channels between school and home.

- Volunteering. Improve recruitment, training, activities, and schedules to involve families as volunteers and as audiences at the school or in other locations. Enable educators to work with volunteers who support students and the school. 
- Learning at Home. Involve families with their children in academic learning at home, including homework, goal setting, and other curriculum-related activities. Encourage teachers to design homework that enables students to share and discuss interesting tasks.

- Decision-Making. Include families as participants in school decisions, governance, and advocacy activities through school councils or improvement teams, committees, and parent organizations.

- Collaborating with the Community. Coordinate resources and services for families, students, and the school with community groups, including businesses, agencies, cultural and civic organizations, and colleges or universities. Enable all to contribute service to the community. (pp. 136-137)

\section{What is parental involvement according No Child Left behind? The ESEA statue}

defines parental involvement as: The participation of parents regular two way, and meaningful communication involving student academic learning and other school activities, including assuring:

- that parents play an integral role in assisting their child's learning.

- that parents are encouraged to be actively involved in their child's education in school.

- that parents are full partners in their child's education and are included, as appropriate in decision-making and on advisory committees to assist in the education of their child, and

- that other activities are carried out; such as those described in section 1118 of ESEA I Parent Involvement [Section 1910 (32) ESEA]

http://www.ncpublicschools.org/docs/program-monitoring/resources/parentinvolveguidance.pdf 
What is the Race to the Top fund? The Race to the Top Fund provides competitive grants to encourage and reward States that are creating the conditions for education innovation and reform implementing ambitious plans in the four education reform areas in the American Recovery and Reinvestment Plan of 2009(ARRP), and achieving significant improvement in student outcomes including making substantial gains in student achievement, closing achievement gaps, improving high school graduation rates and insuring that students are prepared for success in college and careers. http://www.ed.gov/programs/racetothetop/index.html

\section{Purpose of Study}

There are times when parents are not involved in their children's education. The reasons that parents are not involved are considered issues. The research project will identify issues that keep parents from becoming involved in their children's education. This research will identify issues for parent involvement in early literacy skills. In McWayne's (2004) study of parental involvement and social academic competencies of urban kindergarten students, they found that parental involvement influenced children's success in school (p. 83).

Morrow, Tracey, \& Maxwell's study (as cited by Kaiser 2006) stated:

Awareness about the powerful influence of the family on children's literacy development has gained national prominence in recent years. Increasingly, educators, parents, policy makers, and citizens from all walks of life are being told about the importance of parents reading to their children at home. We have also been told about the critical nature of literacy experiences at home and about the value of parental involvement in children's school experiences from early childhood through adolescence (p. 1) .

The research problem is: Many parents are not involved in their children's early literacy education. They are not getting involved in training their children early literacy skills at home. The children have no support at home. They arrive at school without this training and are 
academically behind those students who have had the early literacy support. The children continue to fall behind in school and lose interest. They stop attending classes and eventually dropout of school with no hope.

My research question is: What are the factors for parental involvement in the support of early literacy skill development for their children?

This research was designed to focus on the factors for parent involvement in early literacy. When these barriers are better understood, some may be alleviated. Several factors will be identified. Through this research, a solution was found to help more parents engage in parental involvement in early literacy.

(McWayne et al., 2004) found that parent involvement has become a greater challenge in recent years as the characteristics of families are changing. Now, more than ever, mothers constitute a significant portion of the work force. More children are also living in singleparent households. Given the protective potential of parent involvement, this research calls for more creative solutions to engaging parents in their children's learning (p. 83). A single parent has less time available to become involved.

Leik \& Chalkkey (1990) conducted the Head Start Family Impact Project which was funded by the Administration for Children, Youth and Families with assistance from the Center for Urban and Regional Affairs, University of Minnesota.

The project started in 1986 in cooperation with Parents in Community Action in the Hennepin County Minnesota Head Start Program. Because single mothers head more than 80 percent of PICA families, only that type of family was sampled. A total of 81 PICA single Head Start mothers and their children participated in two sets of assessments. The data from this study speaks to several policy issues: 
At this point, there is good reason to believe that involving parents in Head Start as co participants with their children, rather than simply as home-based teachers, fosters the type of family environment that helps the children most in the long run. Merely asking parents if they think things have improved is not enough (p. 4).

Fantuzzo (2004) studied the relationship between multiple dimensions of family involvement in early childhood education and classroom outcomes were examined. Participants included 144 urban, Head Start children. The study revealed:

Important relationships developed between the multidimensional construct of parent involvement and preschool classroom, competencies and ethnic minority, urban, lowincome children. Through continued attention to the family- school relationship, educators can build more effectively on the competencies that children and their families bring to preschool classroom content (p. 480)

McWayne (2008), conducted a study which examined the relationship between family demographics and the level of satisfaction with school contacts as possible determinants of multiple dimensions of family involvement in early childhood education. Participants included 171 urban Head Start parents. The results found:

For mothers, having less than a high school education was negatively associated with levels of home-school conferencing. For fathers, primary language spoken was associated with both levels of home-school conferences and school based involvement, with Polish and Spanish speaking fathers participating less compared with their English speaking counterparts (p. 672). 
In an article title "Spanking Head Start", Niesslein (2003) wrote "There's nothing much wrong with Head Start except that it reaches only 60 per cent of the kids eligible for it (p. 8). More children need to be in Head Start.

Merlo (2007) conducted a study title "Parental Nurturance Promotes Reading Acquisition in Low Socioeconomic Status" and found:

Children require cognitive skills (e.g., phonemic awareness, verbal intelligence) and environmental resources (e.g., stimulation, print exposure) to acquired reading. This investigation examined the additional contribution of parental nurturance to literacy development during the transition from preschool to elementary school. Participants were 77 children attending Head Start, their primary care givers and their teachers. The results supported the hypothesis that caregivers nurturance can be an important ingredient in the recipe for literacy. (p. 51).

Lynch (2008) conducted a study titled "Engagement with print: low-income families and Head Start children".

The research examined the types of print literacy activities low-income parents reported engaging in with their four-year old children. There were 38 parents of children involved in Head Start, a preschool program for children from low-income families living in the USA, who participated in the study. The results showed: Geographical backgrounds of families accounted for some differences in the types and frequency of print literacy activities parents reported to engage in with their children. However, there were no significant differences in children's print knowledge based on geographical factors. This research may suggest the important role of preschool and particular parent-child activities in developing children's early print concepts (p. 173). 
Kelley (2004) and colleagues research documented the importance of facilitating early and emerging literacy skills in low-income preschool age children who are statistically at risk for having problems learning to read.

The goal of the study was to examine the effects of an early reading curriculum on the language and literacy skills of preschool-age Head Start children. The Montana Early Literacy Project embeds literacy experiences within the existing routines of everyday classrooms and home life. The MELP group made significantly higher gains in narrative discourse development than did the traditional curriculum group. The practical implications of this research relate to the structuring of classroom and family related experiences that embed language and literacy activities within existing routines and events (p. 60).

When the families have little money, their children need extra support to give them access to opportunities and level the playing field.

\section{Summary}

It is very important for parents to be involved in teaching early literacy to their children. The success of their children is dependent on it. The children depend on their parents for support. This support helps the children develop self-esteem. Parents can model behaviors, which inform their children of their parents' attitudes about literacy, education, and life. All parents are not involved in their children's education. The barriers for parental involvement need to be addressed. Parents can teach their children early literacy skills and become involved in their children's education. 
How is Head Start in West Virginia Different from Federal Government Head Start

The focus of this report was on parental involvement. Head Start is a federal program that promotes school readiness by enhancing the social and cognitive development of children through the provision of educational, health, nutritional, social and other services to enrolled families. Each region decides on the assessment that it will use to evaluate its program.

The West Virginia Head Start Association represents twenty-four (24) Head Start programs statewide. Each Head Start program is unique in providing services to their families to meet the specific needs in the community.

Head Start is a national program started by the U.S. Government in 1965. Although federally funded, Head Start programs in the state are locally operated. Funds are awarded directly to local public and private non-profit agencies to operate Head Start programs. At least 10 per cent of the enrollment is reserved for children who have special needs. It focuses on all aspects of a child's development including, their emotional, educational, social, health, nutritional, and physical needs. Head Start has expanded to include services for pregnant women and children under the age of three. Currently West Virginia receives funding to enroll 394 children in twelve counties for Early Head Start. Services offered by Early Head Start are provided in and out of the home to families with young children and expectant families. They include parent education, nutrition services, case management, and the development of support groups for parents. The goal of Early Head Start is to encourage the development of infants and toddlers by assisting parents to recognize their value as the caregiver and teacher of their children while encouraging parents to set their own personal goals. Head Start programs involve parents of enrolled children in many of the program's operations. Each Head Start program has a Policy Council, made up of parents and community representatives, a decision making body of the organization. Parents are encouraged to volunteer in the classroom and to attend training 
offered to assist them in becoming qualified for a variety of employment opportunities within their community.

Head Start programs seek community partnership agreements with local agencies, organizations, and individuals in supporting young children and their families. In establishing a good working relationship within the community, Head Start programs can increase the resources and expand the services available to children and families. http://wvhsa.stephenkingery.com/

Head Start used to take more poor children. Now foster children are included in the state program. It has fewer poor children. Head Start has changed in that before it only had students from the age of 3 to 4 . Now its program starts with pregnant women and includes infants, toddlers to children who are 3 and 4 years of age. They are taking fewer 4 year olds. http://www.newamerica.net/blog/topics/whats-ahead-head-start Head Start programs look for community partnership agreements with local agencies, organizations, and individuals in supporting young children and their families. In establishing a good working relationship within the community, Head Start programs can increase the resources and expand the services available to children and their families.

Head Start became part of The U.S. Department of Health and Human Services under the administration for children and families. It was identified under the Head Start Bureau under the administration on Children, Youth and Families.

It is obvious that Head Start does affect the parent as well as the child. An obvious corollary to the significance of parental involvement is that not all types of involvement are equally effective. Parental involvement may not be the only type of involvement that is appropriate for Head Start programs. Another important policy issue is how best to capitalize on 
cultural variations so that all children in Head Start receive the most benefits possible. Finally, it is apparent that more research on the family system is needed. http://wvhsa.stephenkingery.com/

\section{Summary}

Head Start is a model program for involving parents in the education of their children. It serves as the bridge, which links the home environment to the school. Head Start has been developing plans to make sure that parents are involved. The funding for Head Start centers is dependent on parental involvement. More educational institutions need to look at the Head Start parental involvement model. When children enter school it is so important for the parents to feel welcomed. The institutions can teach parents many things. Head Start provides support for parents through training. The training is provided through workshops, home visits, and one on one conferences. It helps develop good health habits and provided health assistance for the children.

Everyone is entitled to a good education. Everyone needs to experience success early and throughout life. Children need their parents' support in their education. Without the support of their parents, they do not develop a strong sense of self-confidence early in life. Being successful in school and life should be a goal for all the members of the family.

The literature search on parental involvement factors for early literacy will be divided into three parts: 1. literature on emergent literacy as it relates to the 2 to 5 year old group, 2 . literature on the importance of parental involvement, and 3. literature on the importance of family literacy.

Vanderstaay (2006) studied "the effects of low performance in school and also supported the National Commission on Excellence's study, which emphasized the importance of providing children with nurturing experiences in school" (p. 338). The results of the Vanderstaay study 
showed that "Negative experiences in school were connected with delinquent behaviors" (p.

331). When parents are involved positively the children work towards excelling in school, and they develop self-confidence.

Bowman's (2006) research shows that “Children from low-income families and children from diverse ethnic, cultural, and language backgrounds are at high risk of school failure. They fail because [educators] do not provide them with the kind of educational support that they need" (p. 54) .

Wilson-Jones's (2003) qualitative study of factors that promote and inhibit the academic achievement of Rural African American Males in a Mississippi School found "Parental involvement plays a significant role toward the academic success of students. When parents were involved in these children's education, they tended to achieve better in schools" (p. 11) .

The research supports parental involvement. Children are dependent on their parents to reinforce and to enrich their learning. The children develop confidence.

\section{Research on Family Literacy Habits}

Family literacy is very important. The behaviors and materials that are in the home send messages to the children about literacy. The messages that the homes give to the children have a strong effect on them. Often the messages are non-verbal.

VanderStaay (2006) looked at the effects of low performance in school. Vanderstaay felt that children needed to have positive experiences in school instead of negative experiences. In his research Vanderstaay also wrote, "Longitudinal and ethnographic reading research suggests that the timing of early achievement in literacy may also shape their effect upon the child's life chances. Preschool and home literacy practices may protect children from school failure, antisocial behavior, and risks associated with 
inattentiveness while children establish their first bonds with their schools and teachers" (2006, p. 342).

Weigel, Martin, and Bennett (2006) conducted a study on home literacy and identified three ways to conceptualize the home environment: 1. the limiting home environment, 2. the passive home literacy environment, and 3. the active home literacy environment. In addition, parent level of literacy also has been associated with children's literacy and language outcomes. There are also combinations of these components in relation to preschool-age children's literacy and language skills. (p. 208) .

(Clay, 1983) studied early literacy and developed assessment tools to look at the development of preschoolers. Her findings were: "Those who grow in a literate environment will have prior knowledge about books and print to bring to school" (p. 1).

The National Household Education Surveys Program of 2005 was conducted by the National Center for Education Statistics.

Parents were asked whether anyone in their family had engaged in particular home activities with the preschool child in the past week, including reading, telling a story, teaching letters, words, or numbers, teaching songs or music; and working on arts and crafts. More Asian or Pacific Islander, non-Hispanic preschoolers (age 3-5 and not yet enrolled in kindergarten) were told a story by a family member (91 percent) than Black, non-Hispanic preschoolers (82 percent) or Hispanic preschoolers (84 percent).

More preschoolers (age 3-5 and not yet enrolled in kindergarten) in families where both parents or the only parent spoke English were read to by family members in the previous week ( 99 percent) than children in families where no parent spoke English (89 percent). (National Center for Education Statistics, 2006, p. 4) . 
The Annie Casey Foundation conducts frequent studies in regard to the nation's children's well being. In 2005, it documented "The national percentage of children living in single-parent families was 32 percent, 23 percent for non-Hispanic white, 65 percent for Black/African American, 17 percent for Asian and Pacific Island, 49 percent for American Indian and Alaska Native, and 36 percent for Hispanic/ Latino" (Population Reference Bureau, 2007, p. 29) .

The Annie Casey Foundation (Population Reference Bureau, 2007) listed the following information:

The percentage average for children living in families where no parent has full-time, year-round employment by race and Hispanic origin in 2005 are as follows: National average 34, Non-Hispanic white 27, Black/African American 51, Asian and Pacific Islander 30, American Indian and Alaskan Native 53, Hispanic/Latino 39 (p. 50). The Casey foundation also listed the percentage of children living in poverty (income below $\$ 19,806$ for a family of two adults and two-children 2005) averages. They were as follows: "National average 19, non-Hispanic white 11, Black/African American 36, Asia and Pacific Islander 13, American Indian and Alaska Native 23, and Hispanic /Latino 29”(p. 52). Roberts, Jurgens, \& Burchinal's (2005) study examined how 4 specific practices (i.e., shared book, reading frequency, maternal book reading strategies, child's enjoyment of reading, and maternal sensitivity) and global measure of the quality and responsiveness of the home environment during the preschool years predicted children's language and emergent literacy skills between the ages of 3 and 5 years. The global measure of overall responsiveness and support of the home environment was the strongest predictor of children's language and early literacy skills and contributed over and above the specific 
literacy practice measures in predicting children's early language and literacy development (p. 345).

Kaiser (2006) conducted a study based on four Latino family literacy projects in Oregon and California.

The purpose was to identify common factors that have contributed to successful program development and implementation, as well as ongoing viability of these projects. The results were: "Over all increased family involvement. Increased numbers of fathers participate in the project and their child's academic learning. Extended family members such as grandparents, aunts and uncles, and caregivers, also have more involvement" (p. 304).

Kaiser (2006) also suggested "consider the whole family when developing activities. Invite all family members to participate in the project who are involved in the child's life including aunts, uncles, grandparents, and caregivers" (p. 313).

Scarborough et al's study (as cited by Washington, 2001) found "Joint book reading is considered important for young children because it provides the constant exposure to print necessary to facilitate early print awareness" (p. 217).

Washington (2001) conducted a study of early literacy skills in African American Children and wrote "A young child's home and neighborhood are the most important contexts for early literacy development. ....Before we see a child in school the seeds of early literacy development have or have not been planted at home" (p. 214).

Rachid (2005) conducted a study in which the relationship among parent and child home literacy activities and children's academic functioning was investigated with a sample of 65 elementary-age children with RD. 
The results indicated that although individual child and joint home literacy experiences maybe significantly related to prereading skill (language, phonological awareness) as has been found in other studies - the more direct relationship between home literacy and actual reading achievement is less robust, at least among children with early identified RD. The results of the study also suggest that parent home literacy activities may be a more important factor in understanding child reading than activities involving the child more directly. It may be that the parents' reading activities provide more valid information about the home literacy environment or that parents provide more accurate data about their own reading activities than those of their children (p. 9).

Robert's (2005) study examined how 4 specific measures of home-literacy practices (i.e., shared book reading frequency maternal sensitivity) and a global measure of the quality and responsiveness of the home environment during the preschool years predicted children's language and emergent literacy skills between the ages of 3 and 5 years. Study participants were 72 African American children and their mothers or primary guardians primarily from lowincome families whose home literacy environment and development have been followed since infancy. " The main effect of the book reading strategies indicated that mothers who used more book reading strategies had children with higher vocabulary scores over time between 3 years and entry to kindergarten" (p. 354).

In a study of childhood literacy experiences I African American families, Holt (2000) concluded:

Parents play an important role in a child's early learning in preparation for later academic and occupational achievement. Parents can arrange for their children to have access to reading materials and literacy activities and act as role models; demonstrating positive attitudes toward literacy and other forms of educational achievement (p. 118). 
Haney (2004) studied relationships between parent teaching activities and emergent literacy in preschool children. She concluded: “An understanding of how parents contribute to early literacy skills is paramount for developing early education programs that allow each child to maximize her potential” (p. 227). She supported this conclusion with Adam's study (as cited by Haney, 2004).

One irrepressible interpretation is that the likelihood that a child will succeed in the first grade depends most of all on how much she or he has already learned about reading before getting there - and the interpretation seems soberingly correct (p. 227). These studies support how important the parent is in the child's education and development. Matuszny, Banda, \& Coleman (2007) listed the positive effects of parent involvement in the following areas:

Student achievement, student educational aspiration, the length of time students stay in school, student's drive to increase their independence, parents rating of school, teachers perceived efficacy of their own teaching habits, teachers' perception of parents effectiveness, parents ambition their increase their own educational training, and parent perceived efficacy about their parenting skills (p. 25).

Brasher (1993) conducted a study examining the influence of the family on aspects of literacy development employing qualitative methodology by exploring interactive sibling and parental behaviors used with emergent readers as they developed formal literacy skills. Brasher's findings were:

Having role models, whether parents or siblings, who read seemed to make a difference to all the children, who saw reading as a meaningful activity for all family members, including them. All the children in the study reported that they saw parents and siblings 
reading and writing competently and functionally within their home environment (p. 250).

Ricci (2004) examined the home environments, parental beliefs about reading, children's interests in reading, and the emergent literacy skills of children with Down syndrome. "In this present study, parents of children with Down syndrome tailored their literacy activities to their children's level of cognitive functioning, thus providing an 'MA-appropriate' home literacy environment" (p. 58).

Hoerner (2001) assessed the emergent literacy skills of 50 Spanish-speaking Hispanic preschoolers and to examine home environment variables hypothesized to predict emergent literacy outcomes. Hoerner found "The observed quality of the home environment (e.g., number of books in the house, language stimulation, use of television, etc.) was strongly associated with reported early literacy activities practiced in the home" (p. 64). Regardless of the language or culture the home early literacy skills effect the children. The studies all have the same outcome. Students perform better when they have early literacy skills.

Peinado (2001) conducted a study which investigated the effects of eight variables on the English reading achievement of 66 Spanish-speaking, first grade limitedEnglish-proficient students, intelligent level, oral language skills, initial early-literacy skills, initial reading skills, the teacher's reading instructions method, familial income level, parental educational attainment, and parental occupational status.

"This study provided additional support to the research that educational variables that are manipulable are the best predictors of later reading (p. 96).

All of these studies support the importance of family literacy in the home. 


\section{Research on emergent literacy skills}

The literature supports children learning literacy early. In the research document Preventing Reading Difficulties in Young Children(1998), the Committee on the Prevention of Reading Difficulties in Young Children wrote "Reading is essential to success in our society. The ability to read is highly valued and important for social and economic advancement” (p. 17). "Learning to read and write begins long before the school years as the biological, cognitive, and social precursors are put into place" (The Committee on the Prevention of Reading Difficulties, 1998, p. 43). Some children developmental accomplishments of literacy acquisition are: pays attention to separate, be able to identify letter, recognizes environmental print, shows an interest in books, listens to stories..." (The Committee on the Prevention of Reading Difficulties, 1998, p. 61).

Marion (2004) conducted a study and found that:

Experiences of a child during their first year of life are capable of completely changing the way a child turns out. In terms of developing literacy skills, nothing is more important for young children than regular, daily experiences of face-to-face interactions-being read to, talked to, listened to and comforted (pp. 17-18).

Notari-Syverson's (1996) study concluded "There are other factors that also influence children's reading achievement in addition to early experiences with books and print. They are: storybook reading, letter knowledge phonological awareness, and general language abilities" (p. $6)$.

Won (2000) concluded: "Early education gets children ready to learn. Widespread research shows that success in school is often related to early education experiences that occur before a child enters kindergarten" (p. 68). 
Marie Clay (1983), the founder of Reading Recovery found in her studies "The first essential step towards reading and writing success is to have good preschool experiences available to all children. This would ensure that almost all children entered school easily able to converse with others about the world and how they understand it" (p. 1).

"Research suggests that reading to young children aids in their language acquisition, early reading performance, and later success in school. Other early literacy activities, such as telling stories, may also enhance children's chances for success in school" (National Center for Education Statistics, 2003, p. 24).

Miller (2007) conducted a ethnography study to explore how the imagined spaces of pretend play, children and adults together engaged in literacy practices. Specifically this study sought to fine out: When and how does children's pretend play create opportunities for children to learn literacy practices? How do children mediate their own literacy learning?

The research provided the realization that when adults position children during pretend play, children can engage in literacy practices and participate in literacy events beyond what they usually do or can do.... Adults can easily shift children from an imagined authoring space while pretending with the children and other people. This shift allows children to appropriate strategies far beyond those they can learn during decontextualized activities (p. 190).

Hsin (2007) conducted the study which investigated whether phonological awareness instruction, based on Phonological Awareness Training for Reading was effective in improving the phoneme blending, phoneme-segmentation, and word reading skills of preschool children at risk for reading and disabilities. Three preschool children at-risk for reading disabilities participated in this. They were pulled out during classroom free playtime. They received fifteen minutes of instruction five days a week. 
This study showed that the preschool children aged between 5 and 6 years old that were identified as at-risk for reading disabilities could be taught pre-reading skills by explicit phonological awareness instruction. The pre-literacy skills improved by phonological awareness instruction included phoneme blending, phoneme-segmentation, and word reading (p. 189).

\section{Research on effectiveness of parental involvement with emergent literacy skills}

Parent involvement in teaching their children early literacy skills cannot be emphasized enough. They are their children's first teacher. All parents must be involved in teaching their children early literacy skills. Their students are prepared to learn as a result of the early literacy training that they receive at home. If they don't receive early literacy skills, training at home, they start school behind their peers.

Trevino conducted a case study titled "Against all Odds: Lesson from Parents of Migrant High Achievers.”

It examined the nature of parent involvement in five Mexican-origin, migrant families with highly successful children. He found the parents were very involved in their children's lives. He made the following findings for those students who were high achievers: The migrant parents had the following beliefs: 1. It all started with a vision, 2. Parents are the first teachers, 3. Graduating from high school and college is not negotiable, 4. Keep the main thing the main thing, 5. No one's going to give you anything on a silver platter, 6. Respecto (Respect) and 7. Be proud of who you are, 8. Religious faith, and 9.You don't need to spank your children (Trevino, 2004, pp. 8-10) . Neuman (2006) conducted a study and found "Variations in resources had little_almost nothing to do with achievement inequity. Instead family characteristics and socioeconomic status contributed more to learning that schools actually do." (p. 179) . 
Sheldon's (2005) research found: "Six types of parent involvement in a comprehensive program of school, family, and community partnerships: 1. parenting, 2. communicating, 3 . volunteering, 4. learning at home, 5. decision-making, and 6. collaborating with the community" (Sheldon \& Epstein, 2005, p. 197).

"Research has shown that teenagers who have children are less likely to complete high school than those who postpone childbearing until adulthood."(National Center for Education Statistics, 2003, p. 86).

Epstein, Majoribanks, Walberg, and Olmstead's study (as cited by Bailey and Associates (Bailey, 2004) had demonstrated that various techniques of involving parents in their children's school experience improves student outcomes.(p. 173).

Epstein's study (as cited in Epstein, 1985) collected survey data from 613 fifth grade students indicating that:

When teachers are leaders in parent involvement and when parents become involved, the students reported having: more positive attitudes toward school, and more regular homework habits, more similarity between the school and family, more familiarity between the teacher and the family, and more homework assigned on weekends" (p. 22).

Edwards (1999) conducted a study which collected data from a five year examination of a funded initiative which aimed at raising pupil achievement in numeracy and literacy through parental involvement across 70 schools in the Local Education Authority. The aims of the initiative were as follows:

- To raise levels of achievement in literacy and numeracy through further development of home /school /community links.

- Through collaborative teamwork to identify factors for raising levels of achievement. 
- To disseminate successful strategies and processes for overcoming and removing these barriers.

- To raise levels of achievement in literacy and numeracy through further development of home /school /community links.

- Through collaborative teamwork to identify factors for raising levels of achievement.

- To disseminate successful strategies and processes for overcoming and removing these barriers. (p. 329).

Vincent \& Tomlinson's findings (as cited by Edwards, 1999) supported the theory that “parental involvement is under analyzed and under theorized.” (p. 338) .Tharp \& Gallimore's findings (as citied by Edwards, 1999) were "parental involvement is expensive” (p. 338).

Swaps findings (as cited by Kaiser, 2006) "points out that the positive effects of parent involvement are sustained across grade levels (preschool through high school), in programs that are home-based or school based, and for low-income as well as middle-income families" (p. 20).

Epstein's study (as citied by Kaiser, 2006) observed that “...most schools embrace the concept of partnership, but few have translated their beliefs into plans or their plans into practice" (p. 20).

Luppe (2007) conducted a study to extend the knowledge of the relationship between movement and cognition by examining the impact of a sensory-motor program on the literacy skills of first grade learners from one elementary school in East Tennessee.

The implications as a result of the study were:

Movement is one of the underlying components of brain-based learning. Perhaps the findings of future movement studies will not only substantiate the research has already been done but convince educators that making time for movement appeals to a child's 
bodily -kinesthetic nature and can prime the brain for an optimal learning experience ( $\mathrm{p}$. 67).

Mahoney (2007) studied an early intervention training program that is being integrated into the master's degree social work program at Case Western University. It was written: "Parents need to play an important role in early intervention services to have a significant effect on children's developmental and social-emotional well being” (p. 9).

Desimore (1999) conducted a study which was titled "Linking Parent Involvement with Student Achievement: Do Race and Income Matter?" As a result of their research, "The findings of the study suggest that effectiveness of particular parent involvement practices differ according to race-ethnicity and family income" (p. 25).

Crawford (2007) conducted a study that examined the perceptions of parents whose children attended a Virginia Preschool Initiative (VPI) program concerning parental involvement with the purpose of informing and strengthening school and family partnerships. The findings: were:

Parental involvement is highly contextual and, involving individual teachers, administrators, parents, and other concerned adults. Because a parent's involvement in her/his child's learning and schooling is influenced by her/his perceptions of teacher outreach and practices, and because decision-making in this area requires direct input by parents on barriers and facilitating factors to their involvement, this research gathered data on parent's perceptions of parental involvement across the Commonwealth of Virginia (p. 138).

Solorzano (2007) studied the access and factors for parental involvement: Latino and Caucasian Parent perceptions. 
This study emphasized the importance of knowing parent identified factors for parental involvement in order to better involve them in their children's education. Often times, as it was found in this study appropriate structures and strategies do not exist for involving parents appropriately. In fact, schools may actually facilitate the exclusion of parents by establishing activities that require specific majority-based knowledge, behaviors and expectations, which are often presumed to be unproblematic. Therefore, it is particularly important for school personnel to be educated as to the logistical and structured barriers that face Latino parents, which may go beyond those encountered by English-speaking families (p. 66).

Overall, the results of this study indicate that regardless of parent reported involvement, parents in general, and Latino parents in particular, express the desire to be more involved. Therefore, effective communication and solid positive relationships between parents and teachers, along with structural changes, which may reduce logistical barriers, will be essential for successful-school family partnerships (p. 66). Adelman (1994) analyzed home involvement in the schools in his study of intervening to enhance home involvement in schooling.

Adelman's (1994) classification of three types of factors for parental involvement served as a priori categories for analysis (a) impersonal; (b) personal; and (c) institutional. Impersonal barriers are those practical barriers that are logistical in nature, such as one's work schedule, economic constraints, or inability to find appropriate childcare, as well as a parent's personal or family health problems that may prevent involvement. Personal barriers, on the other hand, may include a parent's perception of limited education or knowledge to support a child's learning mistrust of the educational system, lack of social support (such as being a single parent), cultural or language barriers, among other 
personal barriers that may limit involvement. Institutional barriers result when a school does not have a policy supporting parental involvement or when school staff do not encourage parental involvement (such as asking parents to volunteer at school), or when parents feel isolated by institutional elements such as the existence of parent "cliques" (p. 276).

Olvera (2003) conducted a quantitative study that examined the factors for educational involvement in one group of Latino parents. The respondents included 31 Latino parents of children under the age of 12 years of age. Olvera's research indicated that:

Parental involvement is vital for academic success. However what is equally important is fostering a relationship between the school and the parents. Barriers to educational involvement of Latino parents may inevitably lead to the high numbers of Latino dropouts. Unfortunately, the barriers are a result of the daily norms that are fortified by the mainstream society. Although the findings of this research indicated that most of the respondents are actively participating in their child's education it is important to note that previous research still indicates that Latinos continue to face limitations and an unequal access to higher education for a number of reasons, some of the reasons being discrimination and alienation which continue to be nourished by the society's cultural norms (p. 36).

Shears (2006) conducted a study to examine factors for parental involvement from the perspective of educators as well as parents. A convenient sample was taken from the population of elementary schools in a Central Florida county. Parents of students from ethnic minorities were involved.

The findings showed that parental factors for more involvement in their child's education...were (a) their own or family members' health issues, (b) lack of available 
care for children or other family members, (c) lack of available transportation, (d) conflicting work schedules, (e) inability to communicate effectively in English, and (f) not being appreciated by the teacher when they do make the effort to be involved in their child's education. (p. 61).

Brandon (2006) conducted a study to (a) analyze the alienation experienced by African American parents of children with and without disabilities, and (b) examine the relationship of African American parents to the educational system in order to determine the degree of alienation, if any, they felt toward public education. It represented a cross session of economic levels, educational levels, employment levels, and family composition. The data was collected from four predominate African American churches through the use of a survey. There were 421 participants from a large southwestern city.

The six conclusions were drawn from the study were based on quantitative data that was collected:

1. African American parents do not differ in their perceptions concerning the impact of the five problem categories (personal concerns, work, lack of interest, logistics, teacher/parent relationships) on their involvement in their child's schooling.

2. The placement of a child in general education or special education does not impact the involvement of an African American parent in their child's education.

3. Family economic status does not play a role in the concerns expressed by African American parents concerning their involvement in their child's educational environment.

4. Family composition does not play role in the concerns expressed by African American parents in relation to their involvement in their child's schooling.

5. Parent educational level does not impact the concerns expressed by African American parents in relation to their involvement in their child's school. 
6. Parent employment status does not impact the concerns expressed by African American parents concerning their involvement in their children's education (p. 127). Oum (2006) studied parental involvement and how it influences student learning. The goal was to learn about different strategies that get parents involved in their children's education. Oum found in the study:

There are clearly many critical barriers that impede parent and school partnership. However, both sides need to be proactive because they are dealing with someone's future. Whatever parents and school staff do today will shape the present and the future of our society. Parents and school staff must not let barriers such as culture, language, race, and socioeconomic differences come between each other. Rather, they must work together to break down barriers to close the achievement gap (p. 55).

DeBruhl (2006) conducted a study to examine the attitudes practices, and barriers of parental involvement as perceived by teachers and parents of an urban city middle school. This study attempted to determine if there was a difference between the perceptions of teachers and parents across four-grade levels (fifth through eighth).

A total of 274 parents and 68 teachers of students submitted valid e-mail addresses to participate in the study. Of this amount, 152 parents (55\%) and 49 teacher (72\%) responded to the webbased survey (p. 64) .

Based on the results of this study: (1) parents do not believe that barriers exist, and/or (2) the barriers listed are not barriers for them and/or (3) parents are not being completely honest with their barriers. In addition, parents' perceptions of barriers to parental involvement do not depend on grade levels. Therefore, school administrators should provide various opportunities for students and parents to learn and interact together. Parents should be encouraged to participate as well as be involved in a wide range of 
leadership and decision making positions. In addition, school leaders should provide the opportunities for parents to participate in workshops for self-improvement, educational opportunities, and parenting. This would help parents to identify and remove some of the barriers as their children move up in grade level (DeBruhl, 2006, p. 117).

Copper-Butler (2005) conducted a study to gain an understanding about the minority parents' attitudes about school, barriers that keep them from full participation in their children's education, how schools can help parents become more active, and how teachers can help these parents become more involved in school. This study was aimed to gain insight into the perspectives of a group of women who are rarely represented in scholarly literature in Youngstown, Ohio. Ten African American mothers were interviewed in the study.

The most significant conclusion gathered from this date is that these minority mothers do care about the welfare of their children and are willing to engage in behaviors that encourage and support academic success. This study demonstrated that African American mothers can be resilient and do not have to repeat the malpractices of the last. In this study, these mothers did not blame the school for their inabilities to engage in more parental involvement activities. Instead, they looked to self for strength and direction and for supporting their children's education. They hoped for future opportunities to enhance that engagement and to be ever present for their children. Because the participants either lacked the knowledge or experience to demand provision and support for parental involvement, it is up to the school to take the responsibility to ensure that parents are engaged in their children's education... The teacher needs to invite parents to join in inhome and school activities on a regular basis (p. 68).

Sohn (2007) conducted a study which investigated the multiple ways in which Asian parents are involved in their children's early educational experiences, as well as the relationships 
among SES, child demographics, academics factors, parents' barriers, and the impact of parent involvement practices upon children's school achievement.

The findings of this study suggest that parent socioeconomic status significantly positively influences the types and levels of parent involvement across all the comparative groups. It was addressed that low SES parents were less involved in education in school and in the community. As a descriptive analysis of this student presented, high proportions of Asians were below poverty level, while Asian SES, on average was much higher than White counterparts. In addition, the association of Asian parent involvement and SES was as strong as their white counterparts (p. 179).

Barr (2005) conducted a study to better understand the nature of parent involvement in their children's education by examining patterns of parent trust in school in relation to student developmental status or grade level, and student achievement across three different elementary schools.

The results suggest the school a child attends was significantly related to parent involvement. Furthermore parent trust significantly affects parents' decision to be involved at schools and not others. In general, the school a child attends was a better predictor of parental involvement than parent trust in school. Student achievement and grade level were not related to parent involvements (Barr, 2005).

\section{Summary}

This chapter provided a review of the literature on barriers of parental involvement in early literacy skills. Family habits and family literacy are the most effective ways to express family beliefs in early literacy. Parents are the first teachers of preschool children. The children see what is important in their homes. If their parents read to them and read themselves, they are sending a message to their children that reading is important. If there are books, newspapers, 
magazines, paper, pens, pencils, markers, and other evidence of literacy, the children will know that literacy is important and will imitate the behaviors of their family members.

Early literacy skills are very important for children to have to be successful in learning to read. When children are taught early literacy skills, they will experience success in learning to read. They develop their listening skills when they have stories told to them. They develop listening skills when others read to them. The other early literacy skills are built on listening skills.

Teaching children early literacy skills through parental involvement is very important. Parents have a stake in their children's learning. Through parental involvement they help the children experience success. There are barriers which keep parents from becoming involved. Parents must feel empowered and important. Their attitude about learning affects their children's performance in learning. Barriers must be identified and removed.

Children must experience success in early literacy skills before they enter school. They cannot experience this success without parental involvement. Parents can take their children to libraries, read to their children, talk to their children, buy books and volunteer to help in schools and community programs that their children are involved in. Schools can train parents how to teach their children early literacy skills. They should talk to their children and encourage them to do well in school. Parents should teach children to respect themselves and others.

Some barriers that keep children from having early literacy skills are: parents lack of literacy skills themselves, socioeconomic issues, education level, don't understand the importance of education, jobs, bad experiences that they had in school, race, family member health issues, conflicting work schedule, not being appreciated by the teachers when they do make the effort to be involved in their child's education, inability to find appropriate childcare, parent's perception of limited education or knowledge to support a child's academic needs, 
learned mistrust of the educational system, lack of social support (such as being a single parent), cultural or language barriers, and institutional barriers that result when a school does not have a policy supporting parental involvement or school staff do not encourage involvement.

\section{Method}

The current study explored factors for parental involvement in early literacy. This chapter discusses the methods involved in conducting the research study, categorized as follows: (a) restatement of the research question; (b) research design; (c) instrumentation and protocol for each phase of the study; (d) data analysis and (e) discussions of ethical safeguards (Crawford, 2007, p. 59) .

\section{Participants}

The focus group consisted of eleven parents. Ten were females and one was a male. They were from the Northern Panhandle of West Virginia Head Start Program.

Demographics: The group represented five counties which were a combination of rural and urban locations. Of the ten females, there were nine mothers and one grandmother. There was one father. Ten of the parents were white and one was mixed.

Table 2

Northern Panhandle West Virginia Head Start

\begin{tabular}{lll}
\hline Gender & 1 male & 10 females \\
Relationship of Family Member & 1 father & 9 mothers \\
attending Focus Group & & 1 grandmother \\
Ethnicity & 1 Caucasian & 1 mixed, 9 Caucasians \\
\hline
\end{tabular}

Met Income Criteria for Northern Panhandle Head Start

Through the use of the home literacy survey, conducted in north central West Virginia, data was gathered about factors for parent involvement in early literacy. 
The population of the study was 381 parents of preschool aged children enrolled in north central West Virginia Head Start Programs.

In the survey, parents provided the following information about family demographics: 1) the parent's educational level, 2) employment status, 3) yearly income, and 4) ethnic identity.

Demographic survey results: The participants lived in urban and rural areas; the surveys were completed primarily by females; the majority had high school educations; if employed, the salaries were within the range for Head Start eligibility.

Table 3

North Central West Virginia Head Start

\begin{tabular}{cc}
\hline Gender & Ethnicity \\
\hline 45 males & 326 Caucasian \\
326 females & 15 Black \\
& 7 Hispanic \\
& 2 Asian \\
& 3 Native American \\
& 2 Pacific Islander \\
& 10 Mixed Race \\
\hline
\end{tabular}

Met Income Criteria for North Central WV Head Start 


\section{Research Questions}

The primary research question addressed by this research study is: "What are the factors related to parental involvement in early literacy skills?" The sub questions are: What do parents in Head Start do to support early literacy development in their children? What are the barriers in how parents support literacy development for their children?

\section{Design}

Initially, four questions were constructed to give to 11 parents in a focus group. The questions were about the parents' early literacy skills and understanding of parental involvement. The responses to the focus group interviews were used to fine tune the home literacy survey. The home literacy survey was acquired from Dr. Theresa Holt (and used with her permission). It was revised to meet the needs of the population. The total number of surveys distributed was 381. Data collection was conducted through the distribution of this survey instrument designed by the researcher specifically for parents of early literacy preschoolers. Responses to the openand closed-ended survey items were analyzed using quantitative aspects of content analysis.

The purpose is to find out what the factors are related to parental involvement in early literacy skills and which groups are influenced most by these factors.

\section{Procedures}

1. Contacted Dr. Theresa Holt and received her permission to use her home literacy survey in developing the research.

2. Constructed questions for focus group with dissertation committee chair.

3. Contacted the West Virginia University Institutional Review Board (IRB); took and passed the CITI exam and the BRAAN exam, which inform the researcher of their responsibilities and limitations and Hippa guidelines.

4. The Chair of Curriculum and Instruction signed off on the IRB application. 
5. Completed the IRB application online for permission to begin the research for a focus group in Monongalia County, West Virginia and to do the survey in West Virginia and received an exempt review.

6. Due to being unable to arrange a focus group in Monongalia County due unavailability of Head Start Director, I sought and received IRB approval to change the site to the Northern Panhandle of West Virginia.

7. Traveled to Elm Grove at prearranged time, met with Director and parents.

8. Questioned and listened to the parents, as well as answered their questions, noting their answers and comments.

9. At end of meeting, surprised parents by giving each of them a journal, three children's books, one children's jig saw puzzle and one pamphlet on helping children learn to read.

10. Tabulated the results.

11. Used the information to fine tune the home literacy survey.

12. For three months the survey was placed on the Web Monkey, an online web-based company that manages surveys for a fee.

13. Informed West Virginia State Head Start Director and several local Head Start Directors. Gave them the website address and asked them to send parents to the site to complete the survey. Hard copies were available to them as well. Also gave the web site address to several parents and asked them to complete it. After three months no one had completed the survey.

14. Contacted The State Head Start Director who said that I would have to wait 6 months because the local directors were still too busy and then perhaps they would let me conduct the surveys. 
15. Directly contacted North Central West Virginia Family Resource Director for Head Start who made arrangements for me to conduct surveys in North Central West Virginia.

16. Traveled to a bookstore in Flatwoods, WV to purchase 500 early literacy level books.

17. The research was conducted four days a week for 4 weeks from 9 am -4 pm.

18. To obtain informed consent from study participants, a consent letter was read to them.

19. The parents were asked to complete the survey and received at least one book after completion of the survey. They did not know that they would receive a book.

20. The number of books given out varied at the beginning according to the number of preschool children the parents had with them or at home.

21. The surveys were stopped when the book supply was gone.

22. The data was compiled on an Excel worksheet.

23. SPSS software was used for data analysis.

There were 11 parents volunteers to participate in a focus group that lasted for one hour. They discussed what they felt were the issues, challenges and barriers to parental involvement in early literacy support. The information was noted. The state Head Start director was contacted and given information for accessing the surveys on the web. She had been contacted about the Head Start parents participating in the survey. If for some reason the families did not take the computer survey, hard copies of the survey were available.

Initial contact was made with the state director of Head Start by e-mail and telephone to explain the study's purpose and methods. Permission was granted. A formal letter was emailed to the state director of Head Start. The Head Start director was informed that all the surveys would be completed in 30 days. The information was collected and analyzed using SPSS. The results were reported. 
Parent involvement surveys distributed to Head Start parents following appropriate protocol. To obtain informed consent from study participants, a consent letter accompanied the survey distribution.

The consent letter explicitly outlined the purpose of the study, and the guarantee of participants' confidentiality, and participants' voluntary choice to participate in and withdraw from the study at any time without penalty.

\section{Instrumentation}

In order to yield research data that was valuable to Head Start administrators, teachers, and parents, a survey instrument was specifically designed for parents of children served in Head Start programs. The development of the survey instrument was based on a review of the literature on factors for parental involvement in early literacy, as well as through consultation with an early childhood specialist. The survey items were field tested for clarity and relevance by a group of eleven parents whose children were preschool age. The results of this data were used to develop reliability/validity. The foundation of the survey questions was obtained from Dr. Theresa Holt. More questions were added and some were removed from the original survey. Data was gathered using the researcher-developed survey.

\section{Materials}

Table 4

Focus Group Materials

Eleven journals

Eleven "Literacy begins at home -Teach Them to Read" pamphlets

Eleven children's jig saw puzzles

Thirty-three early literacy level children's books 


\section{Survey}

Appendix A contains the family literacy survey. The survey is divided into three parts.

The first section was Personal History and has eight questions about the family's education, occupation, number of children, income, race, and childhood location.

The second section was Family Literacy and has fifteen questions about books in the home, the number of adult books, the number of children's books, types of children's book, other reading materials, the number of times the child was taken to the library, the number of times that the child is read to, the number of times the child writes, the types of activities the child engages in for pleasure, the number of times the child plays games at home involving reading and/or writing, and how often literacy was used by family members in the home and various ways.

Five hundred early literacy level books Section three was attitudes toward education and one question about if the parent actively participated in their child's school and some reasons that parents do not become involved in their children's education.

\section{Analysis procedures}

The SPSS software was used to tabulate the results. The data was entered into the SPSS software program. The results identified the factors for parental involvement in teaching early literacy skills based on the parents responses. Frequencies of responses descriptive data were summarized.

\section{Summary}

These data were examined to identify major factors that were described by parents as impacting their emergent literacy support for their children. 


\section{Results}

\section{Focus Group}

On April 23, 2009 a parent involvement focus group met in Elm Grove, West Virginia. This group had representatives of the Northern Panhandle Head Start Program which is composed of parents from the following counties: Hancock, Brooke, Ohio, Marshall, and Wetzel.

This focus group was conducted with 11 parents. The group was composed of one grandmother, nine mothers and one father. Some of the parents brought their infants and toddlers with them. They asked very good questions and gave important comments.

Question 1. Talk to me about how you work with your child on his/her early literacy skills.

Most parents talked about reading to their child every day. Two talked about having educational games for their children to play and helping their children play with them each day. They said that they talked to their children. Some said that they don't have time. One mother said that she went to school, had three children, and worked. It was very hard for her to have time to work with her children. Yet, she said that she watched the teachers, she wrote down everything that she saw them do, she bought all the materials that she saw the teacher use and she went home and practiced using the skills that she had watched. Three parents said that they used Little Einstein. One said that she used Leap Frog activities. Several others chimed in that they too used Leap Frog activities and that they were very pleased with them. The parents wanted to know how they could help their children. They wanted to know what kinds of activities they could use to help their children. 
Question 2.What concerns do you have about teaching your child early literacy skills?

All parents expressed the desire to know what to teach their child so that they would be ready for kindergarten. They did not want to teach them the wrong things. They wanted to teach their child how to write their names the way the school required rather than teach the wrong way. Yet, when the students enter kindergarten they were expected to know how to write their name. They said that they had not been informed as to what their children are expected to be able to do before entering kindergarten. All the parents expressed the desire for their children to be successful in school. They just wanted to know how they could help. The parents wanted to know how much time they should use each day to teach and help their children. A parent asked me what the definition of literacy was.

Question 3.What do you consider challenges to teaching your child early literacy skills?

One mother said that she did not know where to start. She said that she had two children: one a boy and the other a girl. She said that her daughter, the oldest, could read. The youngest could not do anything, and he was not interested in learning to read. One mother wanted to know how to get her son interested in reading. Parents commented that the home visits that were made to their homes were very helpful. The staff persons took books and materials to their homes and took time helping parents and talking to them.

Question 4. What do you think would help you in teaching your child early literacy skills?

One couple talked about the fact that they had paid 200 dollars to be taught how to teach their child early literacy skills. Several mothers commented that they could not afford to pay that kind of money.

Many of the parents said that they would have liked to have more hands on training rather than hand outs. They expressed the belief that they would feel more comfortable being actively 
involved in the training. They would be able to ask questions and make sure that they were doing it correctly. Their Head Start Program used the creative curriculum.

Question 1 answer summary. Talk to me about how you work with your child on his/her early literacy skills.

Some parents said they read, played, or talked with their child every day. Other parents imitated what they saw the teacher use. Many parents used Little Einstein or Leap Frog games to help their child learn. Other parents felt they did not have the time.

Question 2 answer summary. What concerns do you have about teaching your child early literacy skills?

Parents want their children to be successful and want to know how to prepare their children for kindergarten. Unfortunately many parents worry because they were not being given a list of expectations. Parents were afraid of teaching them the wrong things or the wrong ways. Parents want to have guidelines concerning how much time to spend helping their children.

Question 3 answer summary. What do you consider challenges to teaching your child early literacy skills?

Parents do not know where to start and have problems with children who are not interested in learning. They found the home visits productive.

Question 4 answer summary. What do you think would help you in teaching your child early literacy skills?

Parents felt that more hands on training would help. They felt that being involved, being allowed to ask questions, and getting confirmation they have done things properly would help them in teaching their children early literacy skills. 


\section{Survey}

From June to July of 2009, research was conducted in North Central West Virginia in a Head Start Resource Center. Four days a week for 4 weeks from Monday through Thursday from 9-4 in the waiting room and in the inner waiting room. They were always asked if they would like to make a survey. The survey was explained before anyone started and the consent form was read to the participant. Questions were answered.

\section{Home Literacy Survey Results}

\section{Barriers Identified by Parents}

Table 5

Summaries of Findings: Most Influential

\begin{tabular}{ll}
\hline Barriers & Percentage \\
\hline Work & $19.3 \%$ \\
Childcare & $13.7 \%$ \\
Time & $13.4 \%$ \\
Money & $9.8 \%$ \\
Too Busy & $5.7 \%$ \\
Transportation & $4.7 \%$ \\
\hline
\end{tabular}


Table 6

Summary of Findings : Remainder

\begin{tabular}{lc}
\hline Barriers & Percentage \\
\hline Health Problems & $2.5 \%$ \\
Location & $2.5 \%$ \\
Lack of Materials & $1.7 \%$ \\
Lack of Interest & $1.1 \%$ \\
Understanding & $0.8 \%$ \\
\hline
\end{tabular}

The purpose of this paper was to identify issues in Head Start parental involvement in teaching their children early literacy skills. All of the research supports the importance of parental involvement in teaching children early literacy skills. The question was: What are the issues for Head Start Parents in teaching their children early literacy skills?

The data revealed that parents need support for their education as well as their children's education. Parents need to improve their reading. Funds should be available to put books for adults as well as children in the homes. A large percent $(71.9 \%)$ of parents who took the survey had been taught to read by their mothers. They had been exposed to early literacy in their homes. The study showed that some adults do not have appropriate books in their homes for themselves and their children.

There should be learning communities where families receive support. These learning communities would inform parents through workshops and ongoing training, involving role modeling and other ways to improve their relationships with their children. Resources would help parents teach their children early literacy skills and encourage parental involvement. Work was a barrier to parents being able to attend the daytime meetings. The Head Start parents could not leave their jobs to regularly attend Head Start programs and therefore missed many learning opportunities. Money and materials are major barriers. Without adequate funds, parents reported 
that they were not able to buy the necessary materials to use to teach their children early literacy skills. Parents also could not afford to hire anyone to help tutor their child when they needed additional help and could not provide it themselves.

Transportation and location were barriers for some parents. Parents were unable to attend parental involvement activities due to lack of adequate or reliable means of transportation or due to the location being inconvenient or too far from where they lived. 


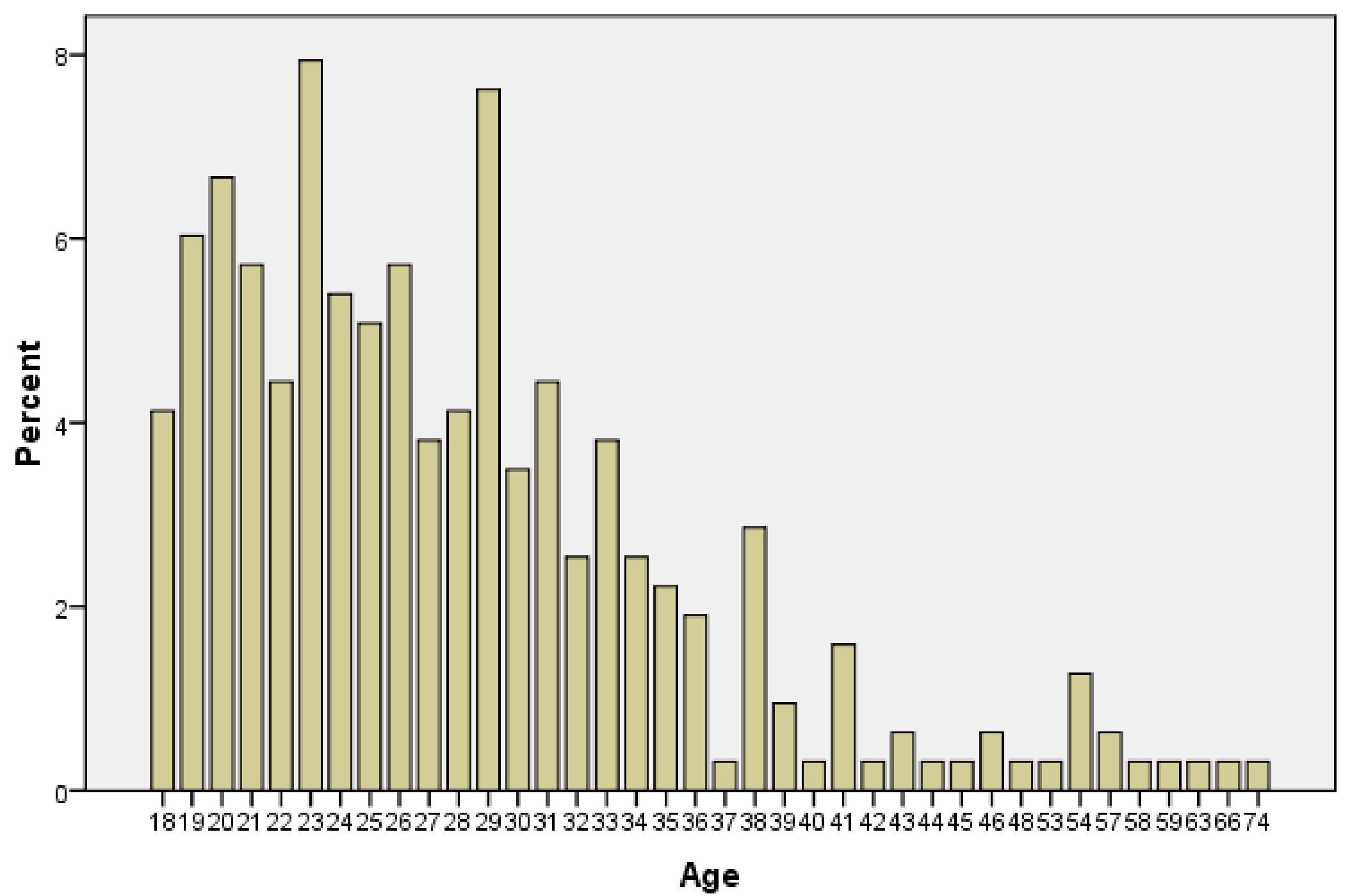

Figure 1. Age of parents taking the survey.

The mode of age was 23. Three hundred and fifteen parents shared their age. 


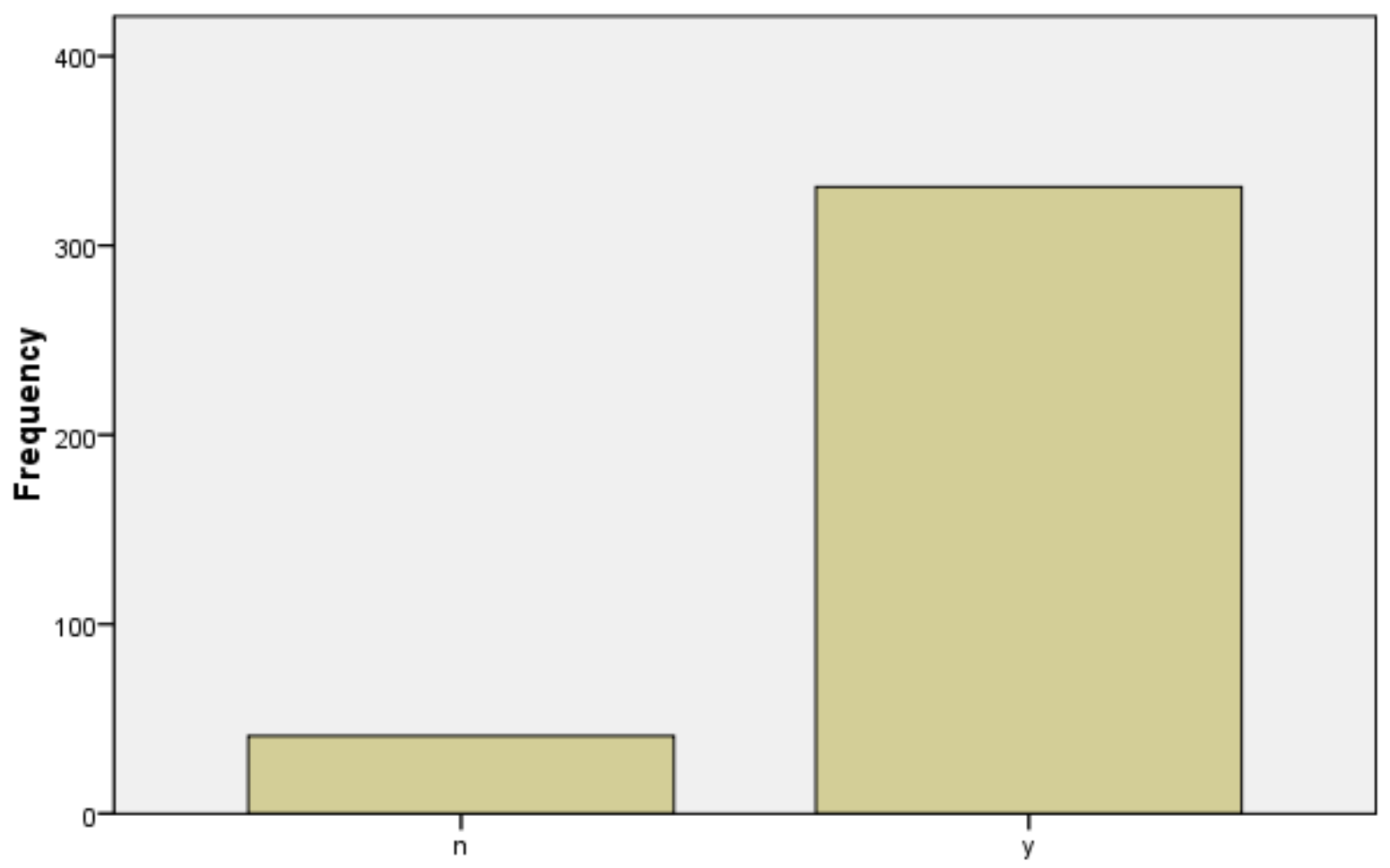

Figure 2. Books for adults in homes.

$\mathrm{n}=$ no books, $\mathrm{y}=$ books in home.

$89 \%$ had books, magazines, and newspapers in their homes 


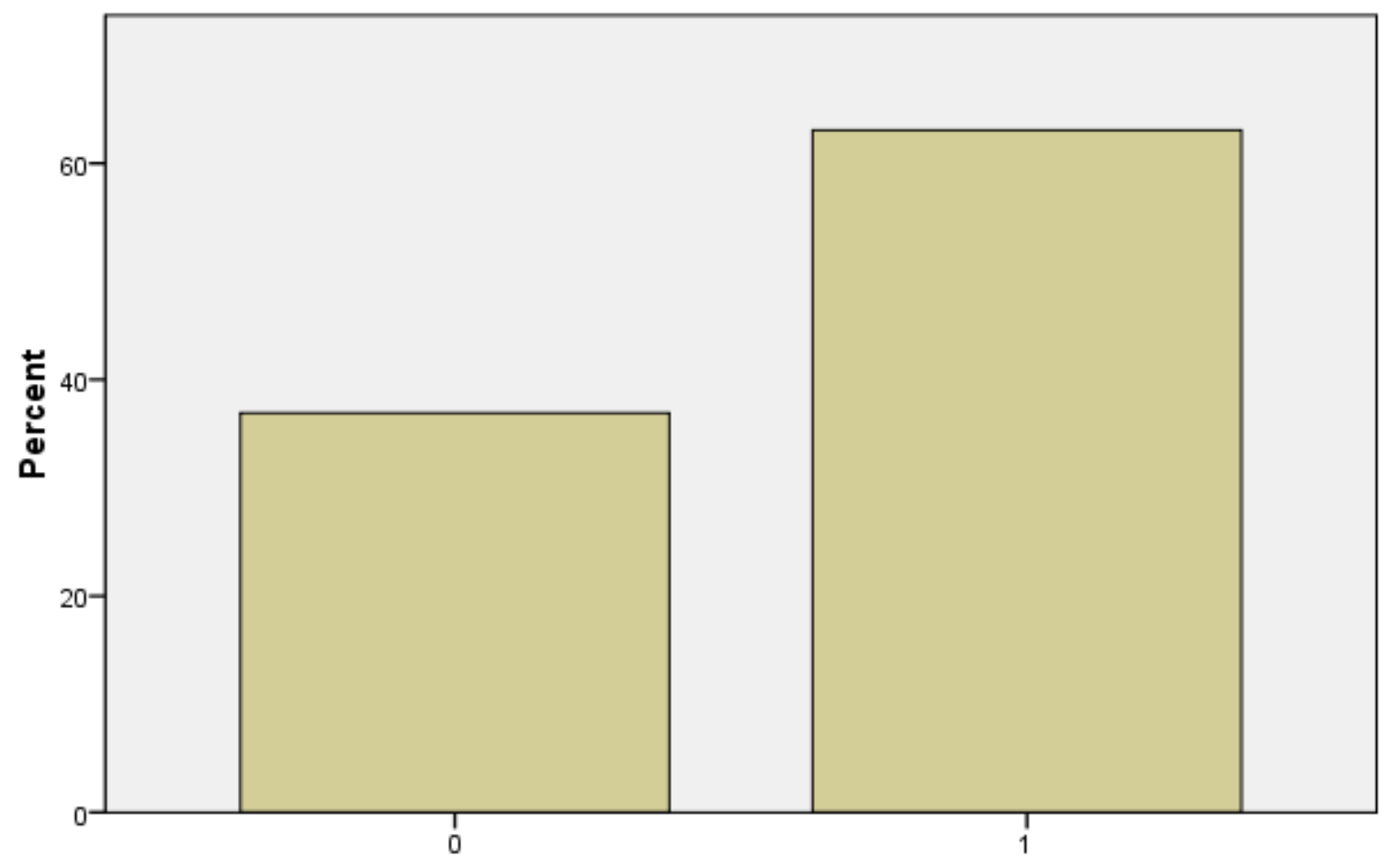

Figure 3. Parents employed outside the home.

$63.1 \%$ parents were employed outside the home.

$36.9 \%$ parents were not employed outside the home. 


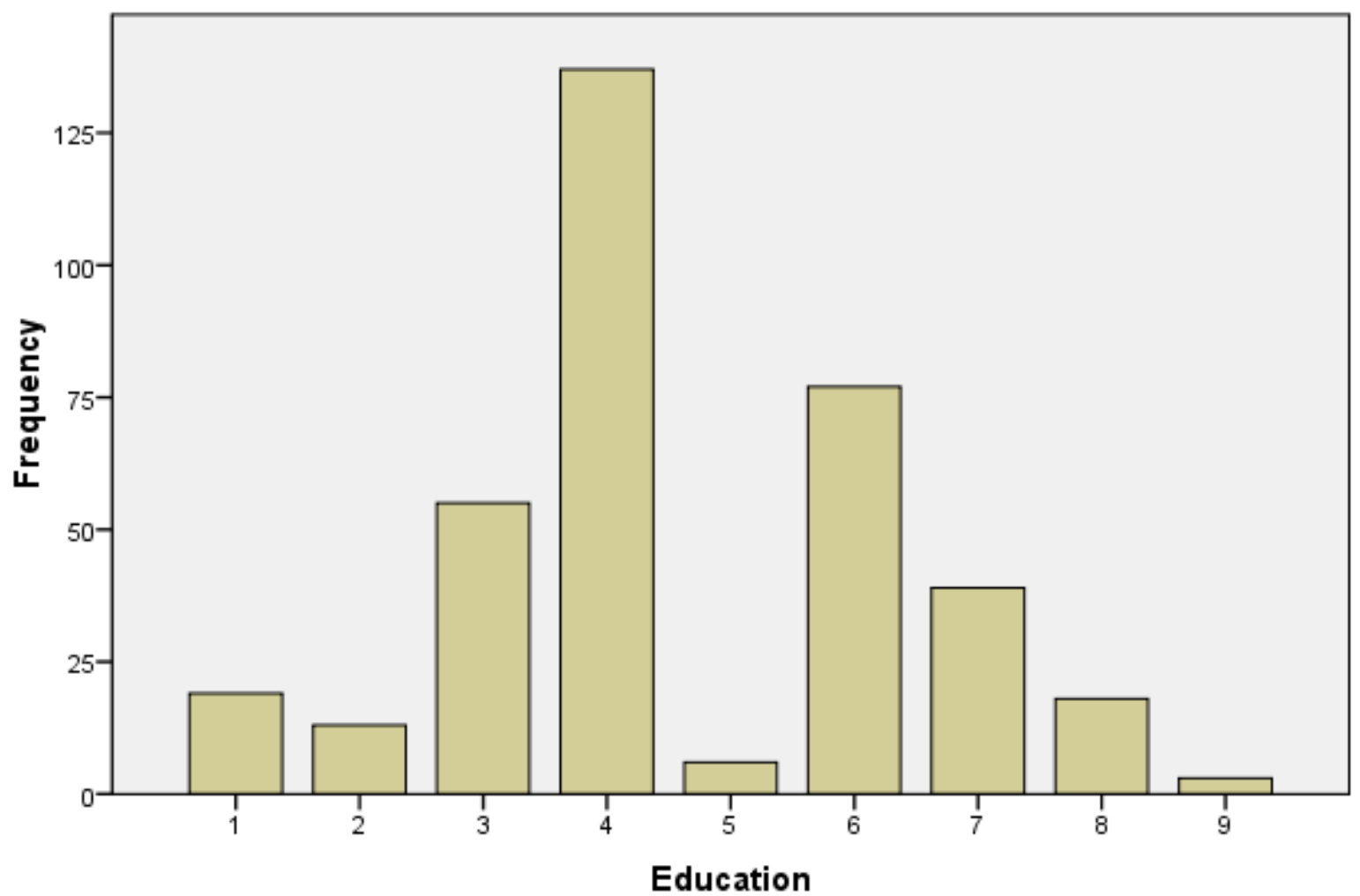

Figure 4. Completed education level of parents taking survey.

1. $5.2 \%$ had graduated from elementary school

2. $3.5 \%$ had graduated from middle school

3. $15.0 \%$ had received their GED

4. $37.3 \%$ had graduated from high school

5. $1.6 \%$ had professional diplomas

6. $21.0 \%$ had some college

7. $10.5 \%$ had associate degrees

8. $4.8 \%$ had bachelors degree

9. $0.8 \%$ had masters degrees 


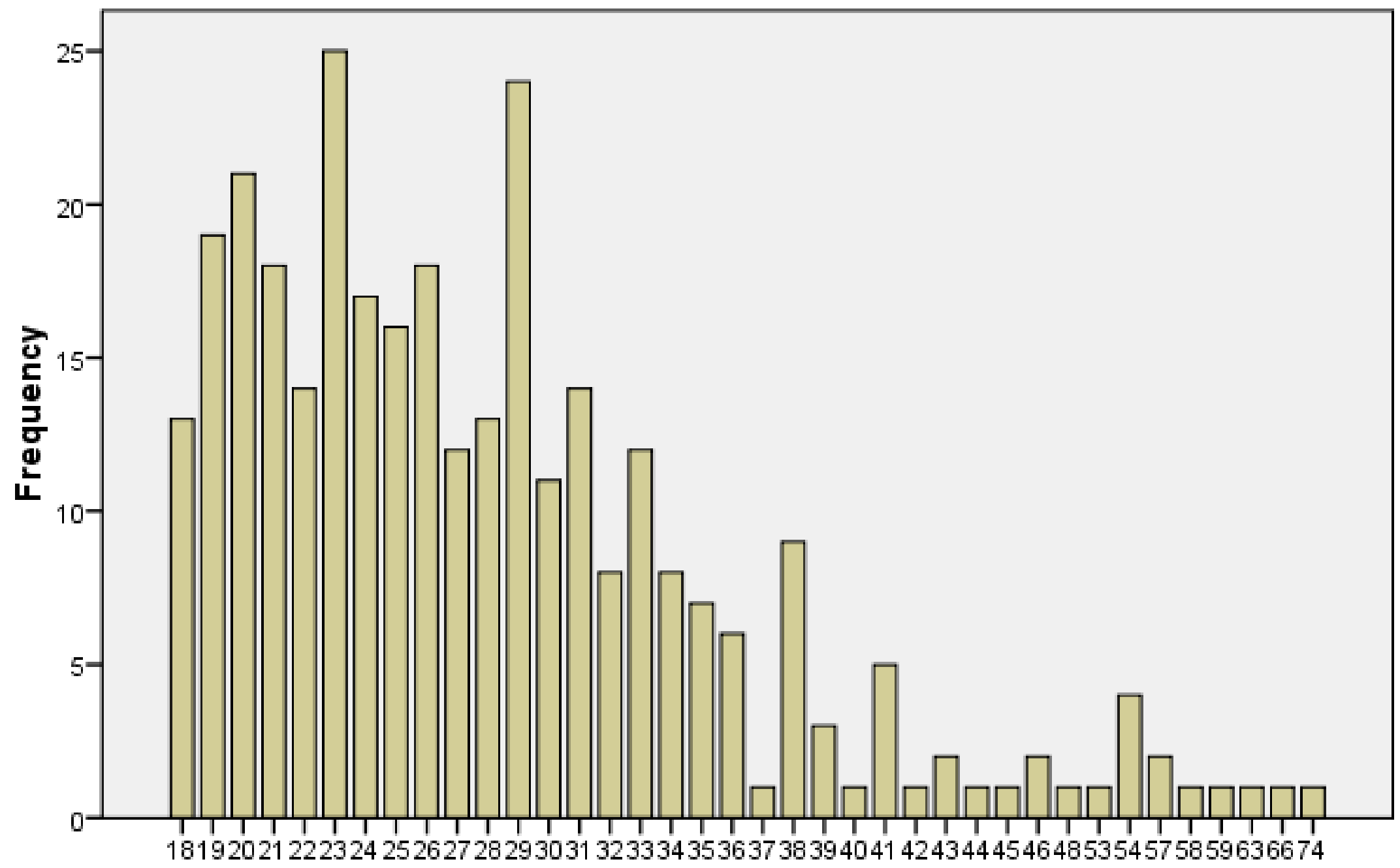

Figure 5. Ages of parents taking survey. 


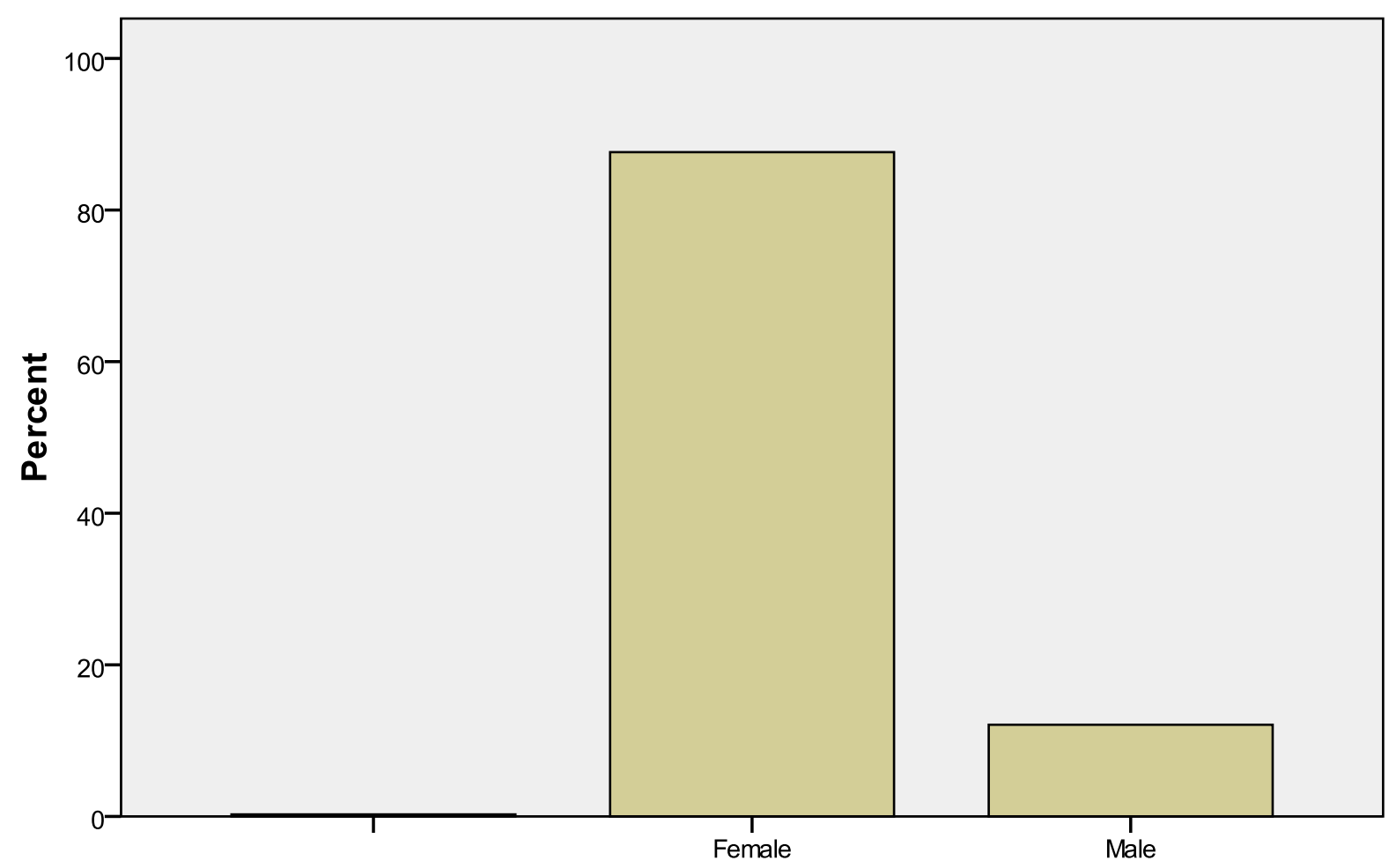

Figure 6. Gender of parents taking the survey.

$87.1 \%$ of parents were female.

$12.2 \%$ were male.

$0.7 \%$ did not supply this information 


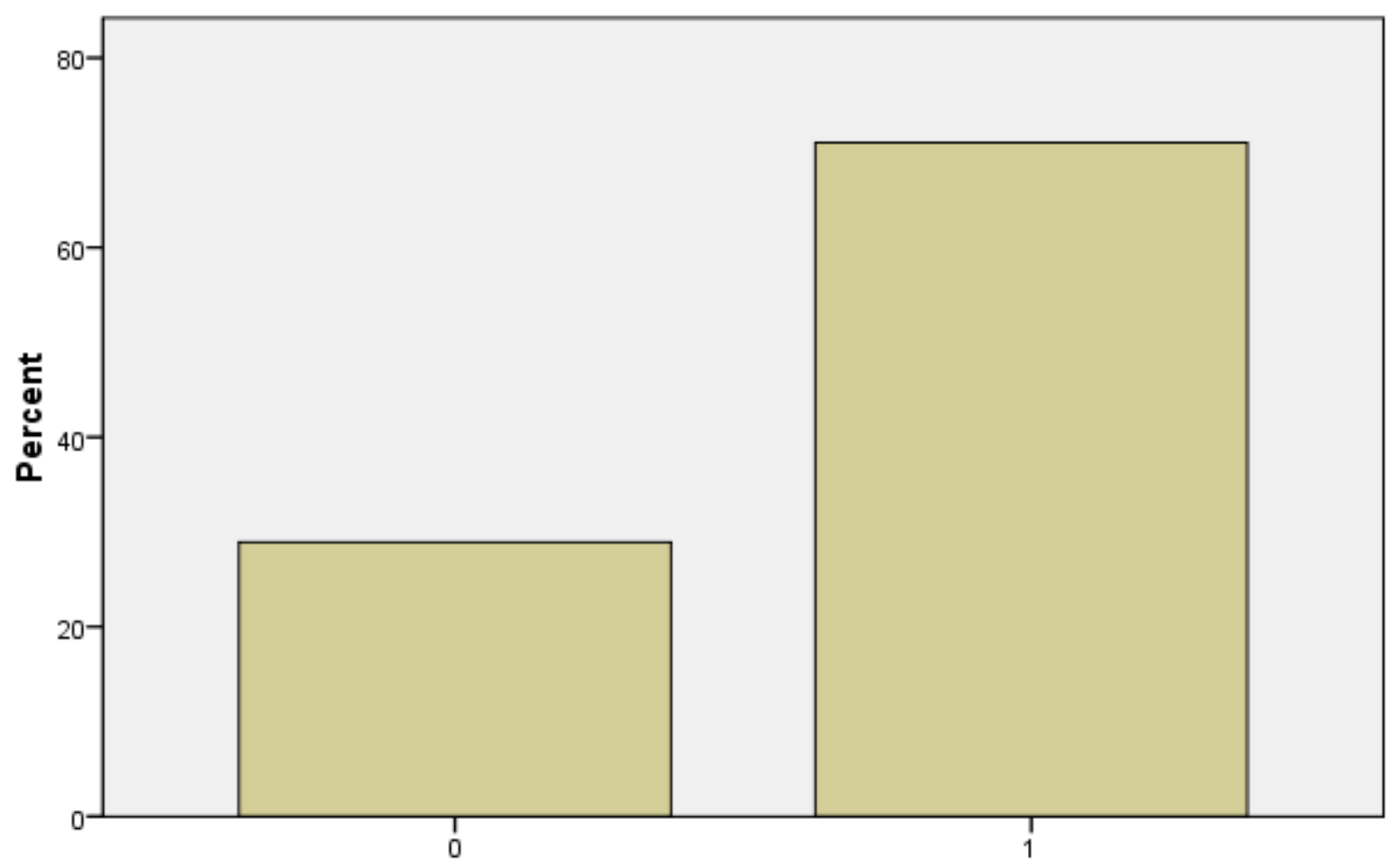

Figure 7. Parents whose mom taught them how to read.

$71.1 \%$ of parents whose mom did teach them to read.

$28.9 \%$ of parents whose mom did not teach them to read. 


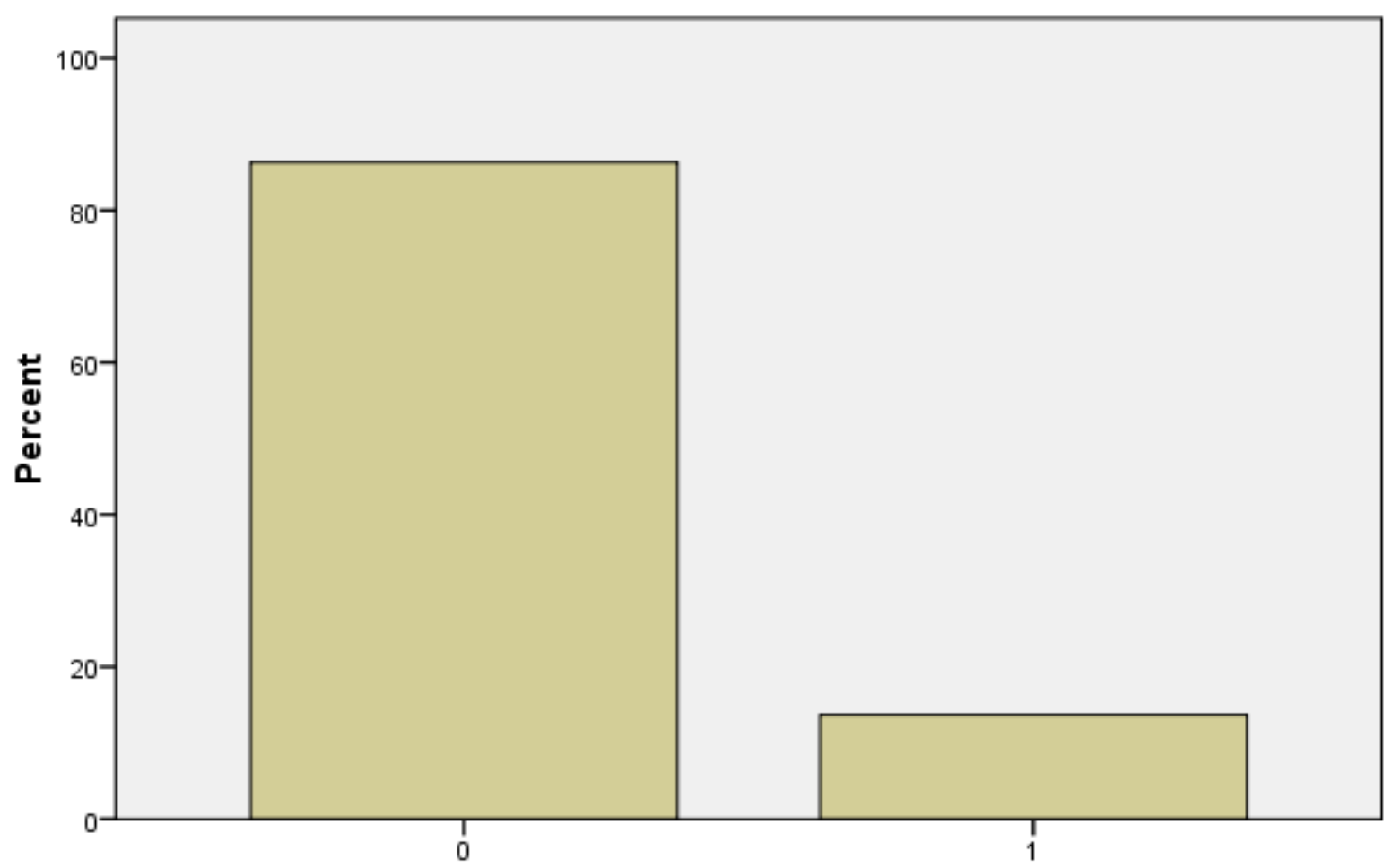

Figure 8. Childcare - barrier to parental involvement.

For $86.3 \%$, child care was not a barrier for parental involvement.

For $13.7 \%$, child care was a barrier for parental involvement. 


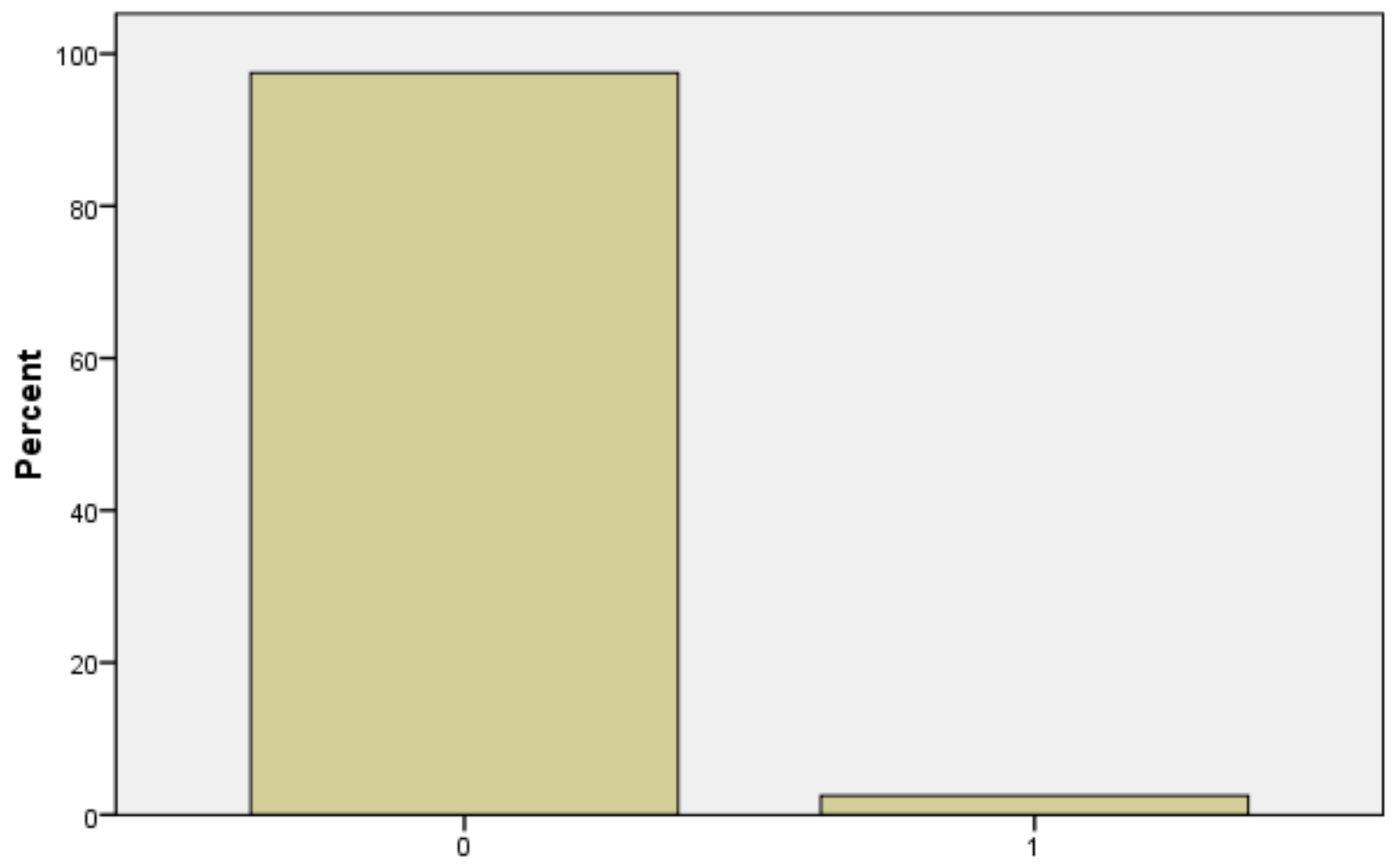

Figure 9. Health - barrier to parental involvement.

For $97.5 \%$ health problems were not a barrier for parental involvement. For $2.5 \%$, health problems were a barrier for parental involvement. 


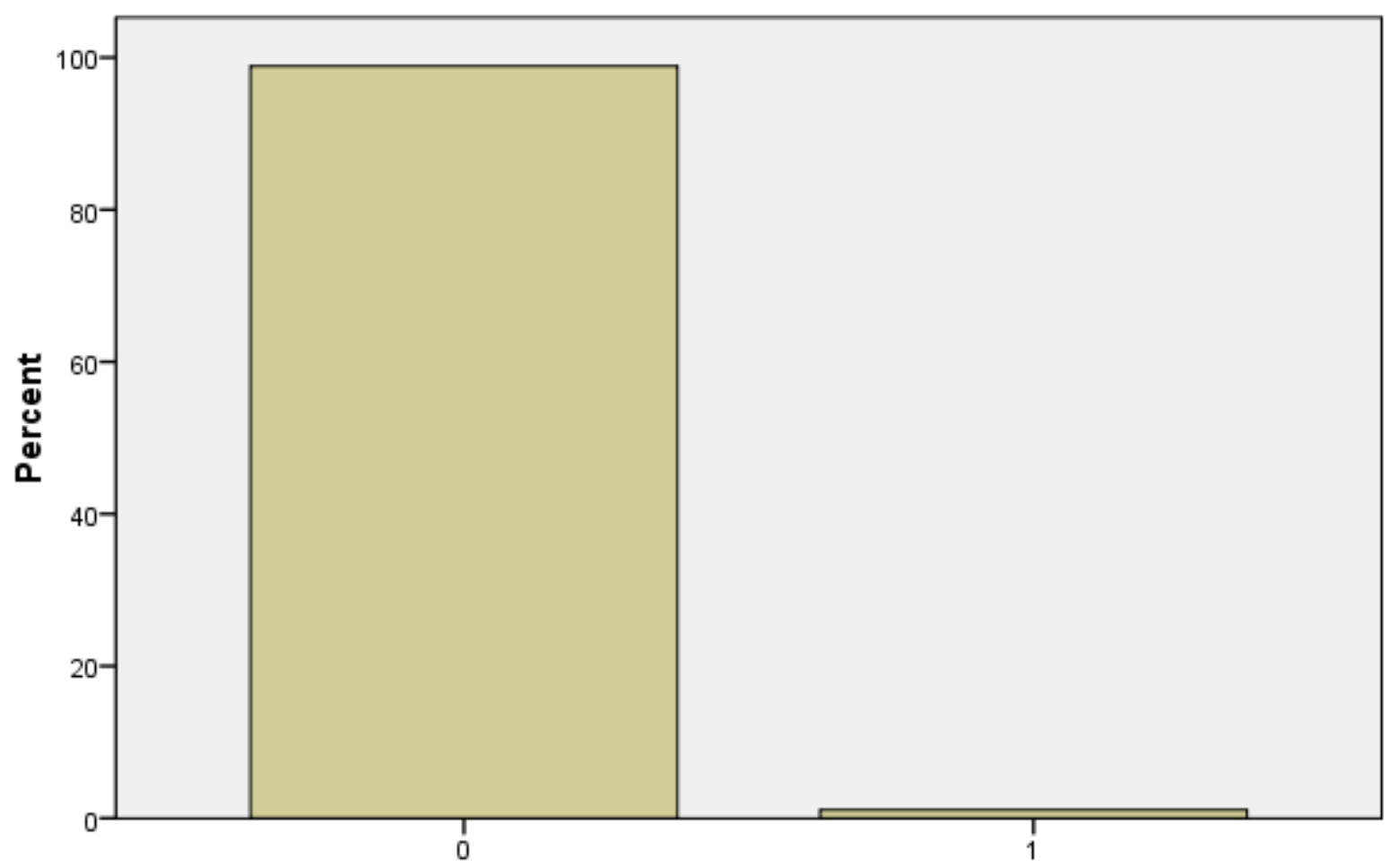

Figure 10. Not interested - barrier to parental involvement.

For $98.9 \%$, lack of parent interest was not a barrier for parental involvement.

For $1.1 \%$, lack of parent interest was a barrier for parental involvement. 


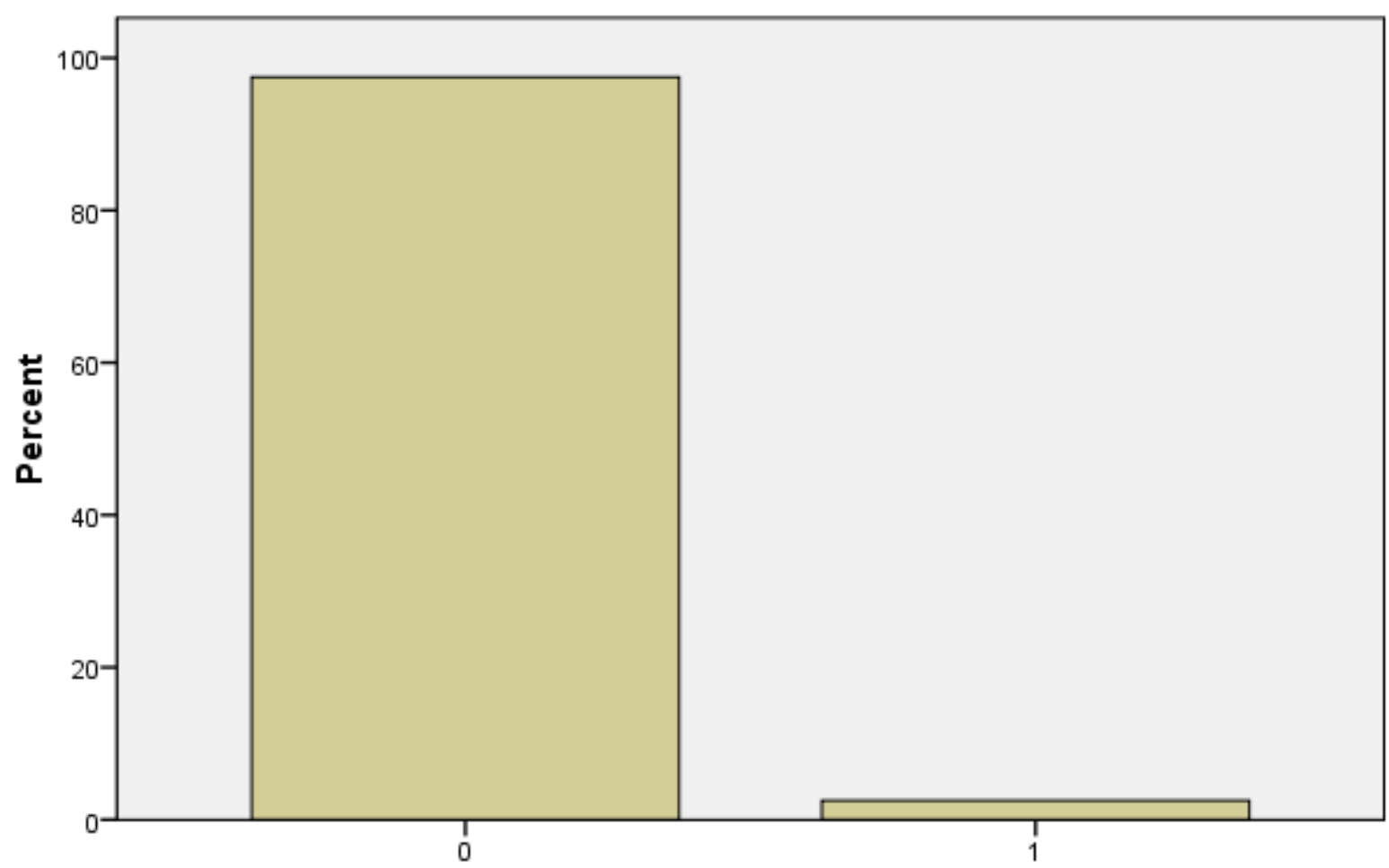

Figure 11. Location - barrier to parental involvement.

For $97.5 \%$, location was not a barrier for parental involvement.

For $2.5 \%$, location was a barrier for parental involvement. 


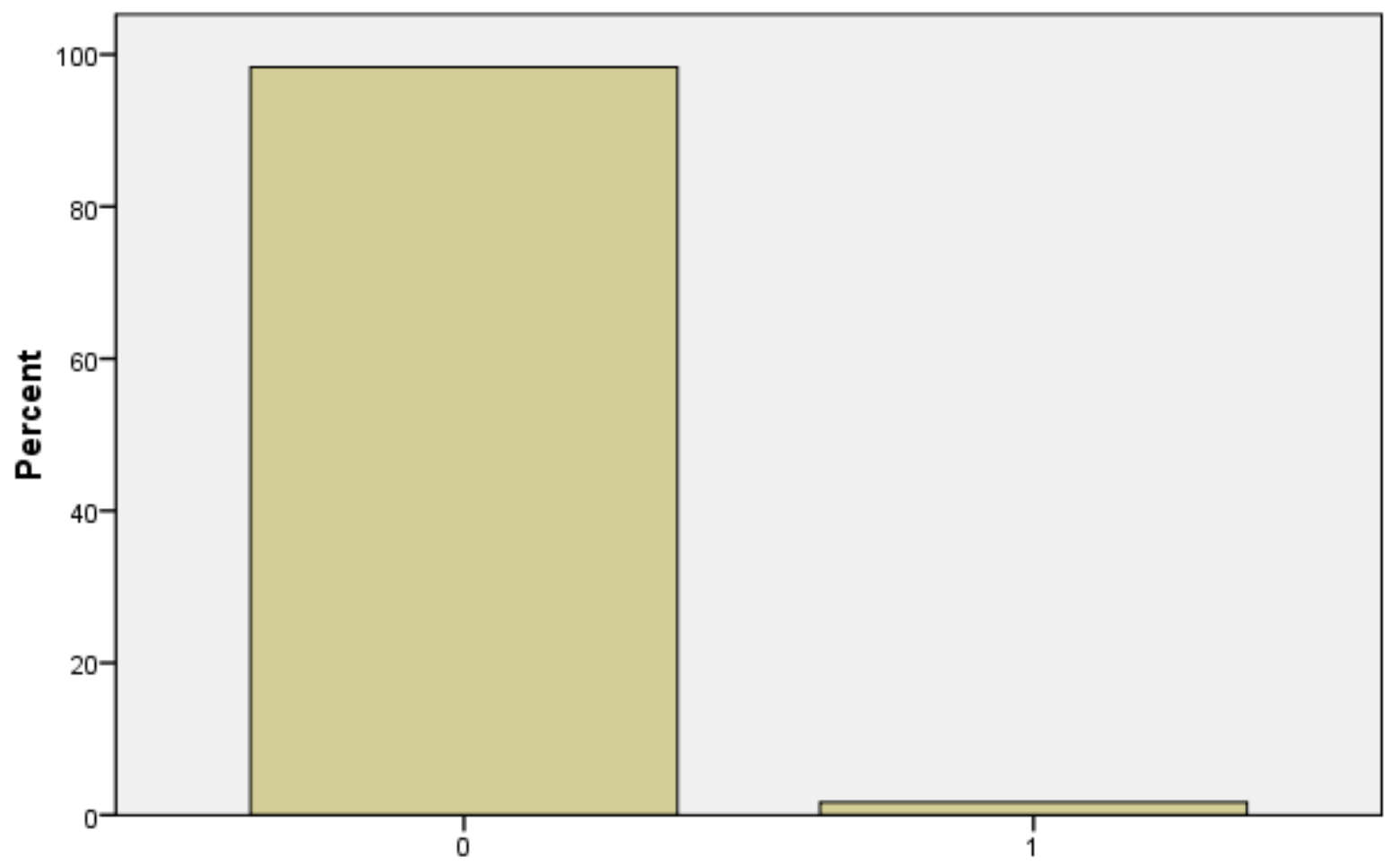

Figure 12. Lack of materials - barrier to parental involvement.

For $98.3 \%$, lack of materials was not a barrier for parental involvement.

For $1.7 \%$, lack of materials was a barrier for parental involvement. 


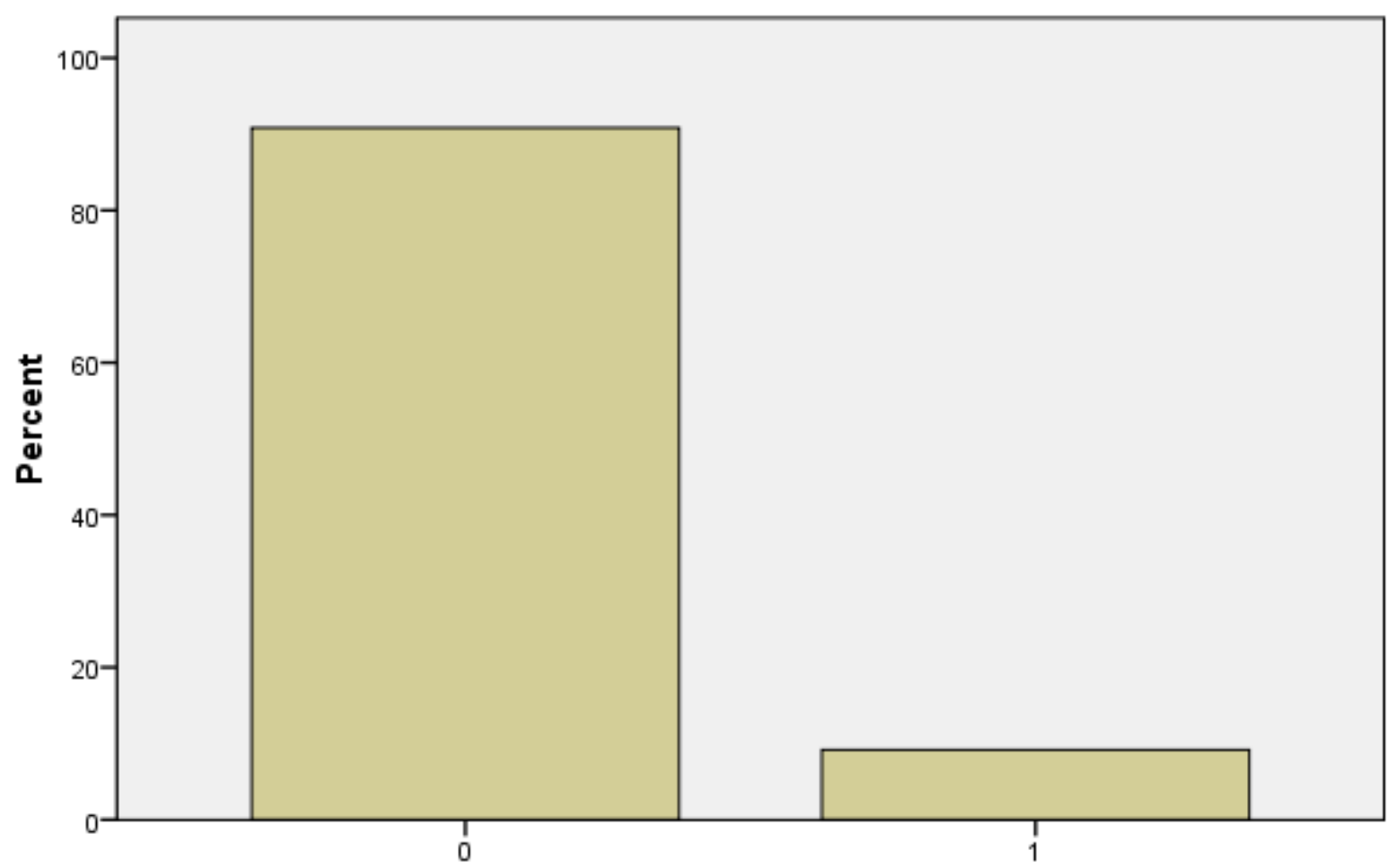

Figure 13. Money - barrier to parental involvement.

For $90.8 \%$, money was not a barrier for parental involvement. For $9.8 \%$, money was a barrier for parental involvement. 


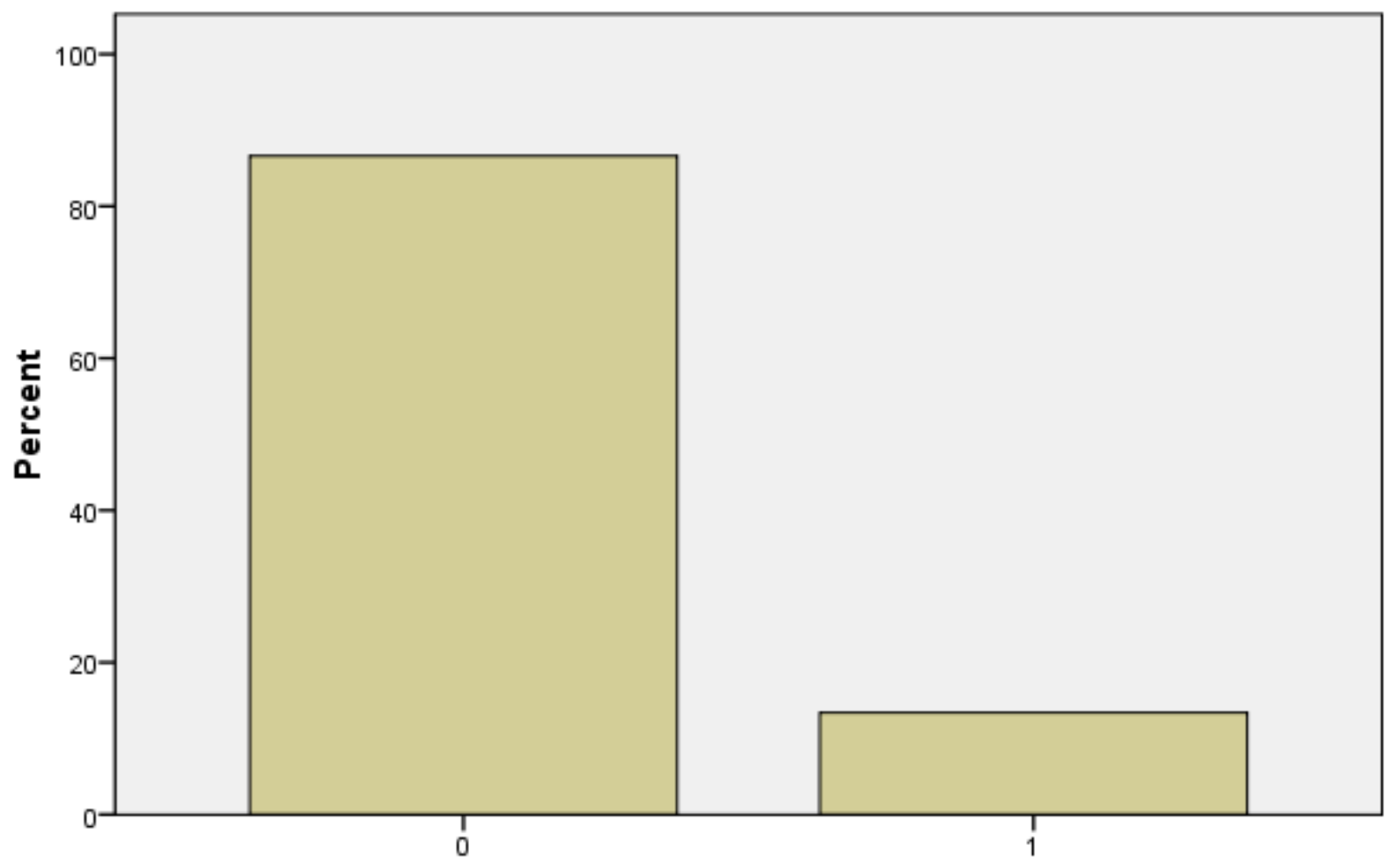

Figure 14. Time - barrier to parental involvement.

For $86.6 \%$, time was not a barrier for parental involvement.

For $13.4 \%$, time was a barrier for parental involvement. 


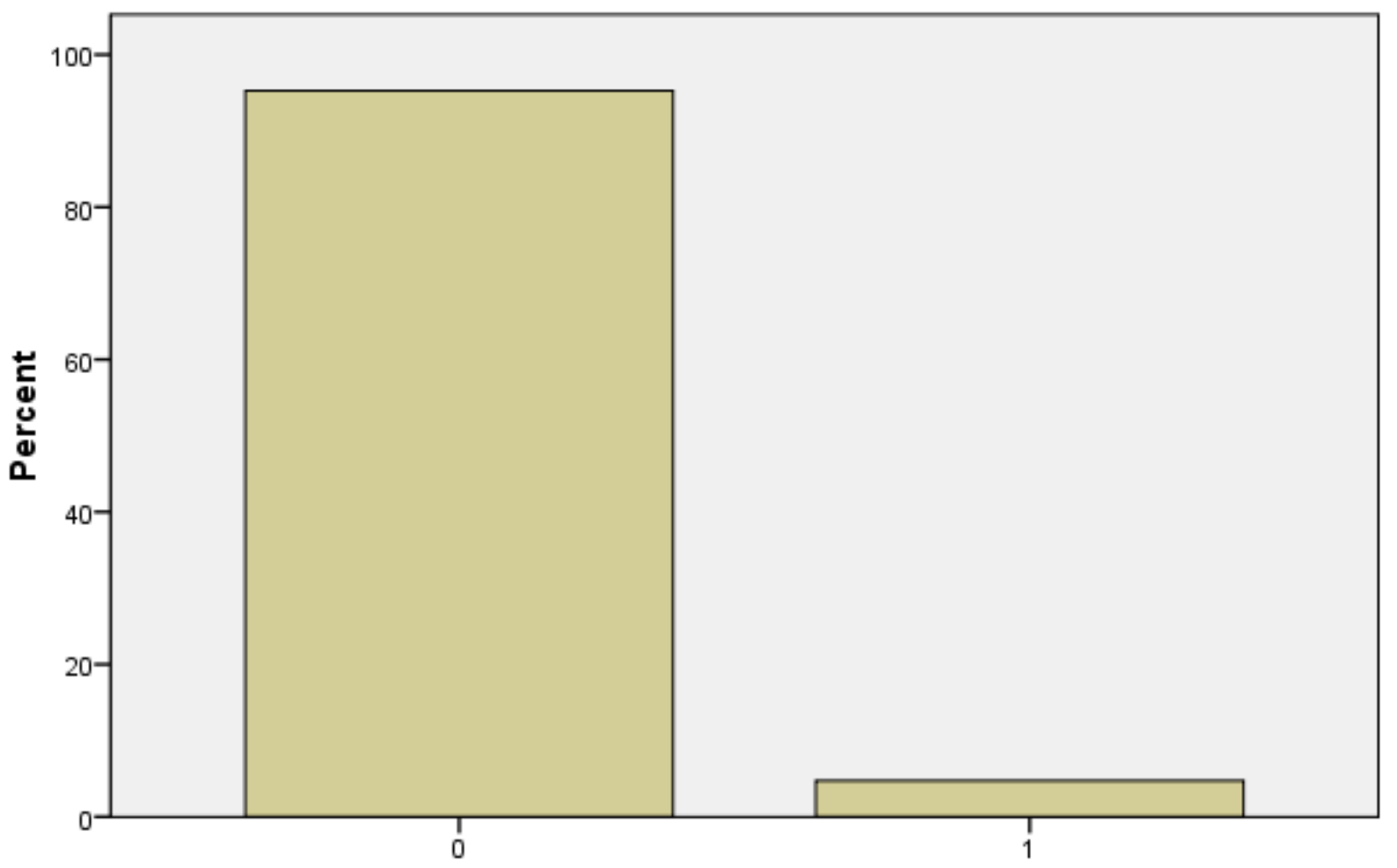

Figure 15. Too Busy - barrier to parental involvement.

For $95.3 \%$, being too busy was not a barrier for parental involvement.

For $5.7 \%$, being too busy was a barrier for parental involvement. 


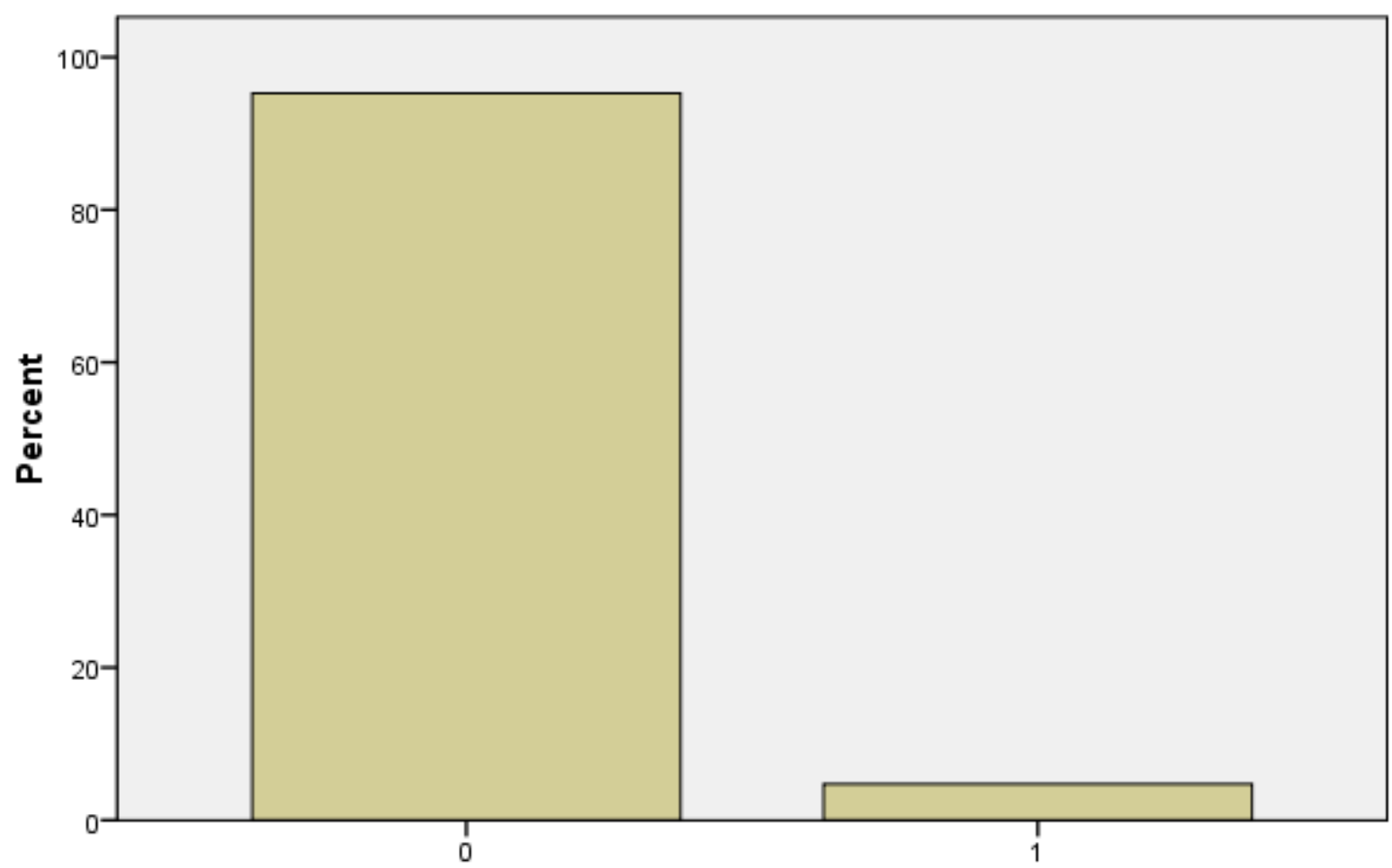

Figure 16. Transportation - barrier to parental involvement.

For $95.3 \%$, transportation was not a barrier to parental involvement. For $4.7 \%$, transportation was a barrier to parental involvement. 


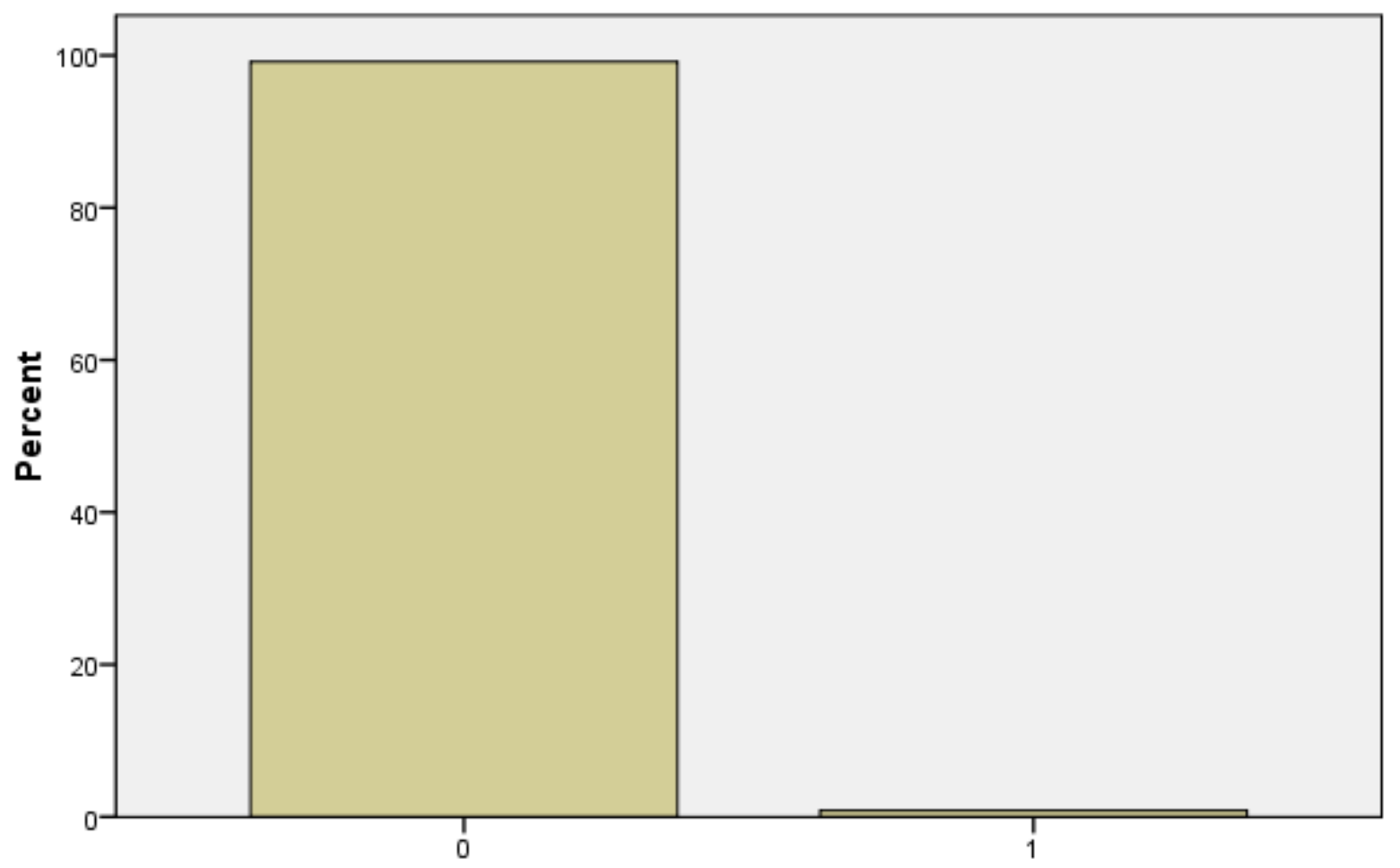

Figure 17. Understanding - barrier to parental involvement.

For $99.2 \%$, understanding was not a barrier to parental involvement. For $0.8 \%$, understanding was a barrier to parental involvement. 


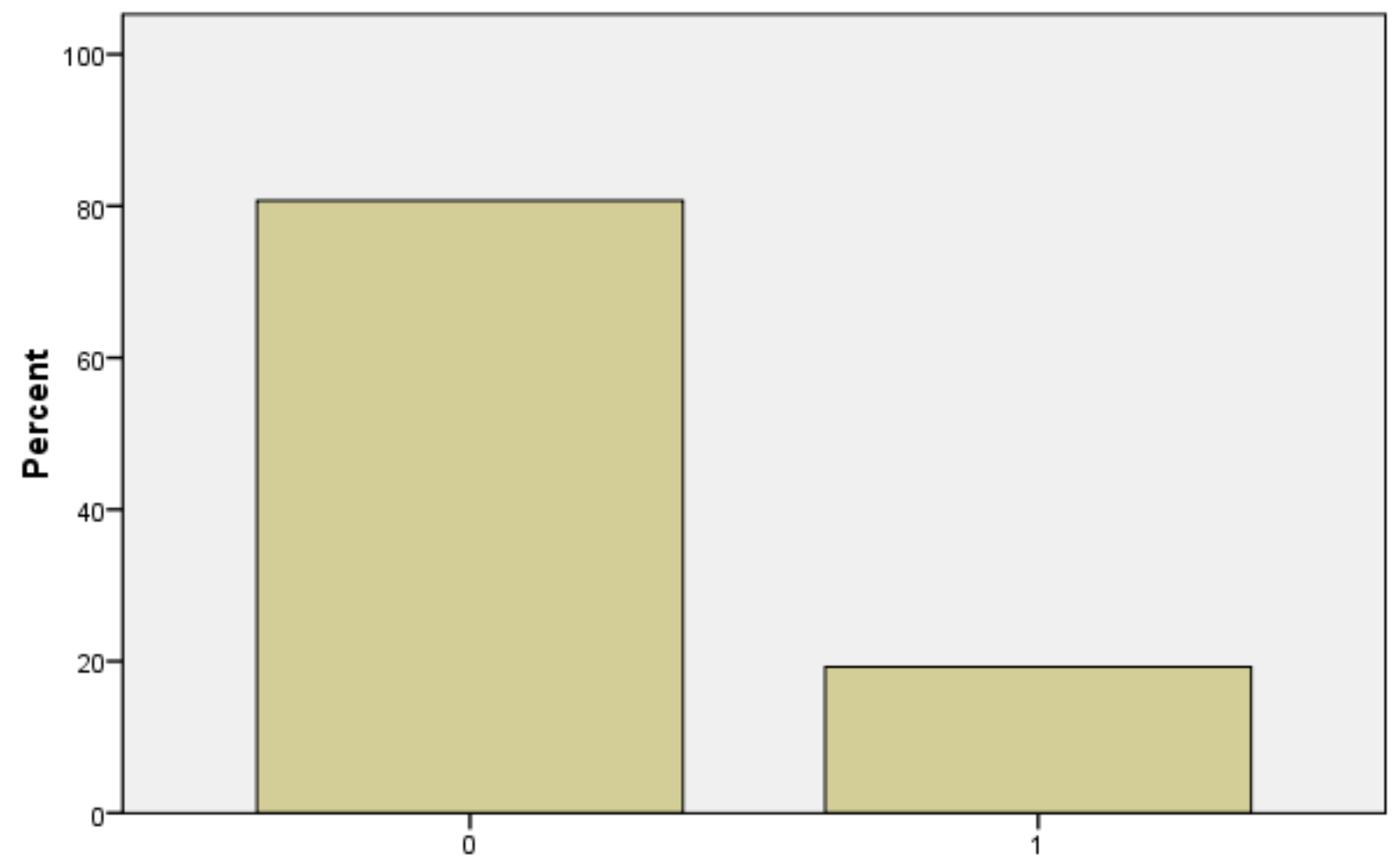

Figure 18. Work - barrier to parental involvement.

For $80.7 \%$, work was not a barrier to parental involvement.

For $19.3 \%$, work was a barrier to parental involvement. 


\section{Discussion}

\section{Conclusions}

The purpose of this dissertation was to identify issues in Head Start parental involvement in teaching their children early literacy skills. All of the research supports the importance of parental involvement in teaching children early literacy skills. Early literacy occurs when children use reading, writing and speaking to communicate needs with others.

The question was: What are the issues for Head Start Parents in teaching their children early literacy skills?

To investigate this question, eleven Head Start parents were invited to participate in a focus group in which they were to identify issues that kept them from helping their children experience success in school. They were given three books and one puzzle as a thank you. A total of 381 parents were asked to fill out home literacy surveys. They received free books as a thank you.

\section{Books in the Homes}

The data reveal that changes need to be made in the way families receive support early literacy development for their children. They need support for their education as well as their children's education. Parents need to improve their reading. Funds should be available to put books in the hands of adults as well as. children. The study showed that some adults do not have appropriate books in their homes for themselves and their children. A large percent (71.9\%) of parents who took the survey had been taught to read by their mothers. They had been exposed to early literacy in their homes.

The data reveal that changes need to be made in the way families receive support of early literacy development for their children. They need support for their education as well as their children's education. 
There should be learning communities where families receive support. These learning communities would inform parents through workshops and ongoing training, involving role modeling and other ways to improve their relationships with their children. Resources would help parents teach their children early learning skills and encourage them.

Transportation and location were barriers for some parents. They were unable to attend parental involvement activities due to lack of adequate or reliable means of transportation or due to the location being inconvenient or too far from where they lived.

Work was a barrier to parents being able to attend the daytime meetings. The parents could not leave their jobs to attend Head Start programs and therefore missed many learning opportunities.

Money and materials were major barriers. Without adequate funds, parents reported that they were not able to buy the necessary materials to use to teach their children basic skills. They also could not afford to hire anyone to help tutor their child when they needed additional help and could not provide it themselves. Head Start Parents need more training and support to help their children develop early literacy skills.

Socioeconomic factor are important. They reflect the results of having limited resources. What do parents in Head Start do to support early literacy development in their children? The things that Head Start Parents do to support early literacy development based on my findings are the following: They read to their children, some talk to their children, some providing paper and writing materials for their children to use at home, they purchase learning games such as "Little Einstein" and "Leap Frog" for their children, they imitate the teachers and some pay for training from local colleges in early literacy. Some have developed large libraries of children's books. 
What are the barriers in how parents support literacy development for their children? The barriers in how parents support literacy development for their children are: they have limited amounts of education some can not read; some did not graduate from high school; some graduated from junior high; some do not have time to help children; they do not have money to buy books and games; they do not have reliable transportation to take their children to the library; few do not care; their jobs do not allow them to help their children; and, some have medical issues that serve as barriers..

Table 7

Barriers Identified by Parents

\begin{tabular}{ll}
\hline Barriers & Percentage \\
\hline Work & $19.3 \%$ \\
Childcare & $13.7 \%$ \\
Time & $13.4 \%$ \\
Money & $9.8 \%$ \\
Too Busy & $5.7 \%$ \\
Transportation & $4.7 \%$ \\
& The Remainder \\
& $2.5 \%$ \\
Health Problems & $2.5 \%$ \\
Location & $1.7 \%$ \\
Lack of Materials & $1.1 \%$ \\
Lack of Interest & $0.8 \%$ \\
\hline
\end{tabular}


The population was Head Start parents. The sample for the survey was Head Start parents from North Central West Virginia. The mode was twenty-three years of age. Most were high school graduates. The bar graph displays the layout of the ages as well as the education of those who filled out the survey. The group identified several issues. The bar graph displays the results of the survey.

The percentage of females (87.6 percent) was higher than males (12.1 percent). There were more females present with their children .

The major barriers for parental involvement according to the survey were money, work, childcare, and time. There should be ways to solve these problems. A survey could be given to concentrate on money, work, and time as variables.

Head Start Parents need to be provided with early literacy hands-on training in ways to help their children.

Phillips and colleagues (2006) conducted a study to determine whether beneficial effects accrue from the use of participation in the Learning Together program. Specifically, effects were sought on (1) children's literacy development, (2) parents literacy development, and (3) parents' ability to assist in the development of their children's literacy. Other objectives included (4) the identification of the time to intervene in children's literacy development for the greatest effect; (5) the documentation of parents' contingent responsivity to scaffold their children's language; (6) the reporting of what parents say about their own literacy experiences and the perceptions prior to, during and after their participation in the program; and (7) the reporting of parents' observations about literacy of their own children now in school. Phillips's study confirmed the incredible powerful combined effect of parents' education and parents' reading ability on their children's reading ability before starting school. (p. 123) 
This information supports the theory that parents have to be involved for children to experience success in early literacy skills.

Parents identified work shifts as an issue that kept them from being involved. Some listed money, location, understanding, time, childcare, lack of materials, health issues, being too busy, transportation, and location. A very few identified having no interest. Head Start parents need more training and support to help their children develop early literacy skills.

Most parents read to their children. Some parents read materials on the adult level. Most read material on the children's level. The charts support this information.

Socio-economic factors are important. They reflect the results of having limited resources.

Sohn (2007) conducted a study which suggested that parents socio-economic status (SES) significantly positively influences the types and levels of parent involvement across all the comparative groups. It was addressed that low SES parents were less involved in education in school and in the community (p. 170).

Children need to be successful in schools so that they can be adults who are able to take care of themselves and their families. They are the future and need all the help that they can get to be good citizens.

\section{Implications}

Parents are children's first teachers. Head Start parents need and want to be taught ways to help their children in early literacy skills. In order for Head Start children to experience success, they need tools which help them achieve this success. Their parents need to be trained in ways that assist their children in being successful in early literacy skills. Parents need to read to their children, take them to the library, model reading and writing, have reading and writing materials in their homes, and have educational games for their children. The success of the 
children depends on the support of the parents who are their first teachers. Schools need to provide workshops to train parents. The workshops should provide modeling experiences for the parents and hands on training. It is very important for parents to be trained in early literacy skills to help their children. Everyone profits from it. The schools, parents, and children are winners. According to Clay, "Children who grow up in a literate environment will have prior knowledge about books and print to bring to school." (Clay, 1983) The activities that go on in the home are important. The success of Head Start children in using early literacy skills is determined by what the parents teach them before they enter_school. All children should enter kindergarten with early literacy skills. Parents need to know what to do to get their children ready.

Parents wanted their children to be successful. They wanted to know how they can help their children. Head Start directors need to develop ways to help parents prepare their children for school. Schools need to help parents become an important/integrated part of the school learning environment.

If parents are not properly supported in getting involved in their children's early literacy education, their children will not be ready for kindergarten. They will not be successful because they will be behind and will have great difficulty catching up. Most will not catch up and will end up in special education classes and eventually drop out of school. This heralds a future of welfare or low income jobs or, worse yet, drugs and incarceration. Of course the women are doomed to repeat the cycle with their own children starting at a very early age. Indeed this is a very sad outlook on life. Marion's (2004) study found "The experiences of a child during their first year of life are capable of changing the way a child turns out." (p. 17) It is important that parents provide children with learning experiences which help them to be successful early in life. An appropriately designed and functioning Head Start program can do this. 
Teaching parents early literacy skills in Head Start will help them help their children develop their literacy skills sooner. They develop confidence in themselves because they have mastered several skills. They are encouraged to improve themselves by getting more education.

It is important for all citizens to be literate. When everyone is successful, our country and everyone in it profits. When parents help their children to gain early literacy skills, they are helping them to be productive citizens. People become self sufficient. They can take care of themselves.

\section{Limitations}

The web-based (Web Monkey) survey response was quite disappointing. Parents did not want to do the electronic form of the surveys. I had not anticipated this resistance.

Some participants did not answer all the questions. Perhaps they instead selected only questions that would cast them in a favorable light, though it was anonymous. Or perhaps the participants may have rushed through the survey, skipping questions since their children were with them and at times acting up. Perhaps the participants may have rushed through the survey, and not answered as accurately as possible since their children were with them and at times acting up.

The West Virginia University students do a lot of work with the Head Start programs in Monongalia County and therefore this population that I had anticipated involving in my research was not available. The Head Start directors reported that the time of year that the research was scheduled to be done was a very busy time for them and they wanted to wait at least for six months before they would ask their parents to consider completing a hard copy of the surveys.

The number of fathers who participated was very small compared to the number of mothers. Offering only a hard copy version of the survey was a limitation. A few parents “didn't 
have their glasses" and declined to take it. This often is an indication of being illiterate or a poor reader. Having a taped version and offering to fill out their answer sheet with their response may have helped.

There was only one focus group and this limited the validity of the data. Three or four focus groups would have helped eliminate this concern. Personal funds were used to finance the research. With a grant or other funding source, perhaps more in-depth research or a larger number of participants or more than one location could be studied.

\section{Recommendations for Parents}

Parents should ask teachers what they can do to help their children and attend all parental involvement meetings. Parents should read to their children every day for ten minutes at least and take them to the library once a week. Enroll the children in read aloud programs at the library. Check out books. There should be materials for writing and reading in the home. Parents should serve as a role model for their children by having reading and writing materials and using them. Conversation should often include the children. There are many free materials that can be obtained from the state departments about helping children. Parents should have a list of questions for Head Start staff when they do not understand. Parents should volunteer at Head Start centers. Parents should explain to Head Start officials when they can not attend and explain why. Parents should attend sessions on parenting.

\section{Recommendations for Head Start Programs}

Make sure the families understand all the opportunities that are available to them. Do follow ups of workshops. Make sure the activities that parents are taught are being done correctly. Involve all parents in the programs. Develop a support program for parents when students go to elementary schools. Continue to encourage parents to get more education for themselves. Encourage the parents to ask more questions. Increase the number of home visits. 
Take books to the homes for the parents that address home literacy. Provide more health care for children from Head Start when they are in public schools. Continue to have social workers work with the Head Start families in elementary school. Set up discussion sessions which take place once a week. In these discussion groups parents can ask questions that they need to have answered. Head Start officials need to develop multiple meeting times to accommodate work schedules and provide day care for parents. Transportation should be available to transport parents who have no means to attend parental involvement activities. Incentives such as gift certificates, games, and books (for parents and children) would help encourage parents to try to attend meetings. Adult literacy classes would help parents who can not read or read only a little. Lesson on teaching children early literacy skills would help parents' confidence. Parents need support in teaching their children early literacy skills. Children who do not learn early literacy skills are not successful in K-12 school. This leads to problems in taking care of themselves throughout life. They have to depend on others for their livelihood. A buddy system should be arranged made up of two parents in a group. They could support each other.

Applying for and getting the Race to the Top Funds would be an excellent way to fund projects to help parents and students in Head Start. The funding would provide monies to support providing books for families, getting parents more education, and teaching parents early literacy skills as well, buying educational games for children, providing transportation for parents. It could be used to pay for health care and nutritional services for poor children and families when they go to elementary schools. The parents would benefit from more training. Funding could be used for training as well. 


\section{Recommendations for Further Research}

More research needs to be done to find out what will help parents who work become involved. Also, research could be done to help locate funds for parents who say that money is one reason that they are not involved.

Research should be conducted to determine if the times for parent involvement could be changed to allow for multiple meeting times. Perhaps daycare programs could be included in this as well.

Research should be conducted to locate more money to be used to set up more Head Start Centers. Forty percent of eligible children can't get into a Head Start program due to lack of space.

All these efforts would help children, and support parents in becoming more involved in their children's early literacy development and parent involvement. Providing support for parents in K-12 schools similar to Head Start for elementary families from Head Start might serve as a strong motivator for parents to become involved in school and support them in increasing their education. This would improve the performance of the child and help the parents.

There should be more research conducted on ways to help all Head Start parents get more education.

There should be research conducted to determine if the level of education of Head Start teachers affects how well the students and their parents learn. Currently some teachers do not have a college degree. Perhaps the research will support the idea that all teachers must have at least a bachelor's degree in early childhood education.

Active research should be conducted to identify the best materials and how to use them to teach Head Start children. 


\section{References}

Adelman, H. S. (1994). Intervening to enhance home involvement in schooling. Intervention in School \& Clinic, 29(5), 276.

Bailey, L. B., Steven B. Silvern, Edna Brabham, and Margaret Ross,. (2004). The Effects of Interactive Reading Homework and Parent Involvement on Children's Inference Responses. [Peered Journal]. Early Childhood Education Journal, 32(3), 173-178.

Barr, J. J. (2005). Parental Involvement In Student Learning: Do Student Achievement And Parent Trust Matter? Unpublished Dissertation, Michigan State University.

Bowman, B. M., Evelyn K. (2006). School Readiness and Social-Emotional Development Perspectives on Cultural Diversity Washington, DC: National Black Child Development Institute, Inc. .

Brandon, R. R. (2006). An Exploration of the Alienation Experienced by African American Parents from their child's Educational Environment. Unpublished Dissertation, University of Nevada, Las Vegas.

Brasher, N. L. (1993). Sibling and Parental Behaviors in Literacy Development. Unpublished Dissertation, Claremont University, Claremont, California

Children's Defense Fund. ( 2000). The State of America's Children. Retrieved from Children Defense Fund.

Clay, M. (1983). Reading Recovery A Guidebook for Teachers in Training. Portsmouth, NH: Heinemann Education.

Committee on the Prevention of Reading Difficulties. (1998). Preventing Reading Difficulties in Young Children Washington, DC National Research Council.

Copper-Butler, B. A. (2005). Experiences and Attitudes pf African American Mothers That Affect Parental Involvement. Unpublished Dissertation, Walden University, Toledo. 
Crawford, E. O. (2007). The Virginia Preschool Initiative : Parents' Perceptions of Parental Involvement. Unpublished Dissertation, The College of William and Mary.

DeBruhl, L. M. (2006). Leave No Parent Behind: A Study of Teachers' and Parents' Attitudes, Practices, and Barriers Regarding Parental Involvement. Unpublished Dissertation, Capella University, New York.

Desimone, L. (1999). Linking Parent Involvement with Student Achievement: Do Race and Income Matter? Journal of Educational Research, 93(1), 11-30.

Dewey, J. (1916). Democracy and Education An Introduction to the Philosophy of Education (2nd ed.). New York: Free Press, Simon and Schuster.

Edwards, A. J. W. (1999). Parental Involvement in Raising the Achievement of Primary School Pupils: why bother? [Research Study]. Oxford Review of Education, 25(3), 17.

Epstein, J. L. (1985). Home and School Connections in Schools of the Future: Implications of Research on Parent Involvement. PJE. Peabody Journal of Education, 62(4), 18.

Epstein, J. L. (Ed.). (2001). School, Family, and Community Partnerships: Preparing Educators and Improving Schools Boulder, Colorado: Corwin.

Fantuzzo, J., McWayne, C., Perry, M. A., \& Childs, S. (2004). Multiple Dimensions of Family Involvement and Their Relations to Behavioral and Learning Competencies for Urban, Low-Income Children. School Psychology Review, 33(4), 467-480.

Haney, M., \& Hill, J. (2004). Relationships between Parent-Teaching Activities and Emergent Literacy in Preschool Children. Early Child Development and Care, 174(3), 215.

Hoerner, S. A. (2001). Home Environments and emergent literacy skills of Hispanic preschoolers. Unpublished Dissertation, University of Utah, Salt Lake City. 
Holt, T. T. (2000). A Study of Childhood Literacy Experiences in African American Families. Unpublished Dissertation, Rutgers State University of New Jersey, New Brunswick, New Jersey.

Honig, A. S. (1999, October 19, 1999). Parent Involvement in the Early Years. Paper presented at the Parent Involvement Preconference Luncheon for the Children's Forum, St. Petersburg, Florida.

Hsin, Y.-W. (2007). Effects of Phonological Awareness Instruction on Pre-Reading Skills of Preschool Children at-risk for Reading Disabilities. Unpublished Dissertation, Ohio State University, Columbus, Ohio.

Kaiser, K. (2006). Latino Family Literacy Projects: Developing Home to School Connections Through Children's Literature and Dialogue. Unpublished Dissertation, The University of San Francisco, San Francisco.

Kelley, M. (2004). The Effects of an Early Reading Curriculum on Language and Literacy Development of Head Start Children. [Journal Article]. Journal of Research ub Childhood Education Vol. 18(Fall ), p. 60.

Leik, R. K., \& Chalkley, M. A. (1990). Parent involvement: What is it that works? Children Today, 19(3), 34.

Luppe, K. S. (2007). The Effects of Movement on Literacy. Unpublished Thesis, East Tennessee State University.

Lynch, J. (2008). Engagement with print: Low-income families and Head Start children. Journal of Early Childhood Literacy, 8(2), 151-175.

Mahoney, G. W., Bridgette. (2007). The Role of Parents in Early Intervention: Implications for Social Work. Children \& Schools, 29(1), 7-15. 
Marion, S. G. (2004). A School's Attempt to Include and Reach Families: The Creation, Impact, and Implications of a Family Literacy Program. Unpublished Case Study, University of North Carolina at Greensboro, Greensboro, North Carolina.

Matuszny, R. M., Banda, D. R., \& Coleman, T. J. (2007). A Progressive Plan for Building Collaborative Relationships With Parents From Diverse Backgrounds. Teaching Exceptional Children, 39(4), 24-31.

McGee, L. R., Donald J. . (2003). Designing Early Literacy Programs: Strategies for At Risk Preschool and Kindergarten Children. New York: Guildford Press.

McWayne, C., Campos, R., \& Owsianik, M. (2008). A multidimensional, multilevel examination of mother and father involvement among culturally diverse Head Start families. Journal of School Psychology, 46(5), 551-573.

McWayne, C., Hampton, V., Fantuzzo, J., Cohen, H. L., \& Sekino, Y. (2004). A multivariate examination of parent involvement and the social and academic competencies of urban kindergarten children. Psychology in the Schools, 41(3), 363-377.

Merlo, L. J., Bowman, M., \& Barnett, D. (2007). Parental Nurturance Promotes Reading Acquisition in Low Socioeconomic Status Children. Early Education \& Development, 18(1), 51-69.

Miller, K. K. (2007). Pretend play and literacy learning in one early childhood classroom. Unpublished Qualitative Research, Ohio State University, Columbus, Ohio.

National Center for Education Statistics. (2003). Status and Trends in the Education of Blacks (No. CES 2003-034). Jessup: US Department of Education.

National Center for Education Statistics. (2006). National Household Education Surveys Program of 2005: Initial results from the 2005 NHES Early Childhood Program 
Participation Survey. Washington, DC: U S Department of Education, Institute of Education Sciences.

National Research Council. (1998). Preventing Reading Difficulties in Young Children Washington, DC National Academy Press

Neuman, S. B., Donna Celano. (2006). The Knowledge Gap; Implications of Leveling the Playing Field for Low-Income and Middle -Income Children. [Research Study]. Reading Research Quarterly 41(2), 176-201.

Niesslein, J. (2003). Spanking Head Start, Nation (Vol. 277, pp. 8-24): Nation Company, L. P.

Notari-Syverson, A. A. O. (1996). Facilitating Language and Literacy Development in Preschool Children: To Each According to Their Needs (Paper Presented No. ED395692). New York: American Educational Research Association.

Olvera, M. R. (2003). The Perceived Barriers to Educational Involvement In One group of Latino Parents. Unpublished Thesis, California State University, Long Beach.

Oum, R. M. (2006). Closing the achievement Gap Through Parent Involvement. Unpublished Thesis, Pacific Lutheran University.

Peinado, R. (2001). The effects of student, familiar, and educational variables on the English reading achievement of Spanish-speaking first-grade limited English proficient students. Unpublished Dissertation, University of Oregon.

Phillips, L. R. H., Stephen P.North. (2006). Family Literacy Matters A Longitudinal ParentChild Literacy Intervention Study (1 ed.). Calgary, Alberta, Canada: Detselig Enterprises, LTD.

Population Reference Bureau. (2007). The Annie E. Casey Foundation 2007 Kids Count Data Book: State Profiles of Child Well-Being. Baltimore, Maryland 
Rashid, F. L., Morris, R. D., \& Sevcik, R. A. (2005). Relationship between Home Literacy Environment and Reading Achievement in Children with Reading Disabilities. Journal of Learning Disabilities, 38(1), 2.

Ricci, L. A. (2004). Home Literacy environment, parental beliefs about reading, and the emergent literacy skills of children with Down Syndrome. Unpublished Dissertation, University of California Los Angeles

Roberts, J., Jurgens, J., \& Burchinal, M. (2005). The Role of Home Literacy Practices in Preschool Children's Language and Emergent Literacy Skills. Journal of Speech, Language \& Hearing Research, 48(2), 345-359.

Shearer, K. A. (2006). Parental Involvement: Teachers' and Parents' Voices. Unpublished Dissertation, University of Central Florida, Orlando.

Sheldon, S. B., \& Epstein, J. L. (2005). Involvement Counts: Family and Community Partnerships and Mathematics Achievement. Journal of Educational Research, 98(4).

Sohn, S. (2007). Asian Parent Involvement In the Home, School, and Community and Children's Achievement in the Early Grades. Unpublished Dissertation, State University of New York at Buffalo, Buffalo

Solórzano, L. (2007). Access and Barriers to Parental Involvement: Latino and Caucasian Parent Perceptions. Unpublished Dissertation, James Madison University.

Teale, W. J. Y. (Ed.). (2000). Beginning Reading and Writing Perspectives on Instruction. New York: Teachers College Press

The Committee on the Prevention of Reading Difficulties. (1998). Preventing Reading Difficulties in Young Children Washington, DC National Research Council.

Trevino, R. E. (2004). Against All Odds: Lessons from Parents of Migrant High-Achievers. 
VanderStaay. (2006). Learning from Longitudinal Research in Criminology and the Health Sciences. [Research]. Reading Research Quarterly, 41(3), 328-350.

Washington, J. A. (2001). Early Literacy Skills in African-American Children: Research Considerations. Learning Disabilities: Research \& Practice, 16(4), 213-221.

Weigel, D. J., Martin, S. S., \& Bennett, K. K. (2006). Contributions of the Home Literacy Environment to Preschool Aged Children and Emerging Literacy and Language Skills. Early Child Development \& Care, 176(3/4), 357-378.

Wilson-Jones, L. (2003). Factors that Promote and Inhibit the Academic Achievement of Rural Elementary African American Males in a Mississippi School: A Qualitative Study. Arkansas.

Won, S., Susanne Martinez, Kinda Seraft . (2000). The State of America's Children. Retrieved from Children's Defense Fund. 
Appendix A

\section{Family Literacy Survey}


Date

Participant \#

\section{Family Literacy Survey}

\section{Section 1 Personal History}

1. Education (check last completed diploma or degree)

Elementary School

High School Diploma

GED

Professional Diploma
Associates Degree

Bachelors Degree

Masters Degree

Doctoral Degree

Some college

2. Occupation (be specific)

3. Age 4. Birthplace 5. Male Female

6. Age at which you learned to read: 7. Who taught you to read?

8. Location (s) where early childhood was spent: City State

9. Type of childhood location (s) Rural Suburban Urban

If location changed during childhood, explain why

10. Number of sisters and brothers:

11. Number of parents in your early childhood home.

If other adults were present, who were they?

12. Your income group check the one that applies.

( )

$0-10,000$
( )

$11,000-25,000 \quad 26,000-50,000$
( )

$50,000-75,000$
( )

$76,000+$ 
13. Your race. Please check the one that applies

_ White -non Hispanic __Black_Hispanic _ Asian _ Native American _ Pacific Islanders Mixed Race

14. Education of mother (check the highest completed diploma or degree)

Elementary School

High School Diploma

GED

Professional Diploma
Associate Degree

Bachelors Degree

Masters Degree

Doctoral Degree

Some College

15. Occupation of Mother (be specific)

16. Education of father (check highest completed diploma or degree)

Elementary School

Associate Degree

High School Diploma

Bachelor Degree

GED

- Masters Degree

Professional Diploma

Doctoral Degree

Some College

17. Occupation of father (be specific)

Section II: Family Literacy

Please answer the questions below by circling the appropriate number:

Always(1) Very often (2) Sometimes (3) seldom (4) Never (5) do not recall(6)

18. Which books do you have in your home for your preschooler?

Check all those that apply

Alphabet books

Fairy tales

Bible stories

Number books 
Coloring books

Comic books
Storybooks

Textbooks

Others

19. If these were books for children, approximately how many?

$1-10$ $11-20$ $20-29$ $30+$

20. Are there books in your home for adults?

21. If there are books for adults, approximately how many?

1-10
$11-20$ Over 20

Check all that apply

Biographies

Books of poetry Magazine
Novels Textbooks Newspaper

22. If books, newspapers or magazines were read by adults in your home how often did they include you in discussions about those readings per week?

_0-1_2-5_6-10_ $11-15 \_16+$

23. What kinds of books do you have in your home? Check all that apply.

Write them down on the space provided

24. How often you take your child to the library each month?

$$
\simeq^{0-1} \_2-3 \_4-6 \_7-10 \_11+
$$

25. How often do you read to your child during a regular week?

$$
]^{0-2} \_2-4 \quad 5-8 \_9-12 \_12+
$$

26. How often during a typical week does your child write?

$$
\text { - }-2 \_2-4 \_5-8 \_9-12 \_13+
$$


27. Which activities does your child do for fun in the following for pleasure? Check all that apply.

_ Reading a book

_ Reading a newspaper

__ Reading a magazine

_Looking at TV

_Listening to music

_Conversations with a parent
_ Trips

_. Sports

Movies

Arts and crafts

Talking on the telephone

Writing letters

Other (Explain)

28. How often during a regular week does your child play games at home involving reading and /or writing?

$\underline{0}^{0-1} \mathbf{2}^{2-4}{ }_{-}^{5-7} \_8-10 \_11-12$

29. Indicate how often reading and writing is used by family members in your home in the following ways.

For daily living routines per day (examples: Writing shopping lists, reading recipes, paying bills)
( )
( )
( )
( )
( )
$2-4$
5-7
8-9
$10+$

$0-1$

30. For entertainment (Examples: Reading a novel or magazine)
( )
( )
( )
( )
( )

$0-1$

$2-4$

$5-7$

$8-9$

$10+$

31. For school related activity (Examples: Doing homework, reading child's school papers
( )
( )
( )
()
( )
$0-1$
$2-4$
$5-7$
8-9
$10+$ 


\section{SECTION II: FAMILY LITERACY}

(Continued)

32. For interpersonal communication
( )
( )
( )
( )
( )
0-1
$2-4$
5-7
$8-9$
$10+$

33. For religion (Examples $>$ Reading Bible passages, reading religious publications.)
( )
( )
()
( )
( )
$0-1$
$2-4$
$5-7$
$8-9$
$10+$

34. Other (explain)

( )

( )

( )

( )

( )

$0-1$

$2-4$

$5-7$

8-9

$10+$

\section{SECTION III: ATTITUDES TOWARD EDUCATION}

35. How do you actively participate in your child's schooling (for example, ,. etc)-Check all that apply.

_ attend parent-teacher conferences

_

_ serve on committees

member of the PTO/PTA

other (explain)

36. What are some reasons that you do not become involved in your child's education? Please check all that apply.

_ Work shifts

_Time

_Childcare
Lack of Materials

Too Busy

Health issues 
_ Money

Other(explain)

Location

Transportation

_ Understanding

No interest

Do you read to your child? Yes or No

What do you read?

SECTION IV: COMMENTS ABOUT ANY ITEMS IN THE SURVEY 
Appendix B

Head Start Program Performance Standards 


\section{HEAD START PROGRAM PERFORMANCE STANDARDS}

45 CFR 1304.40(a) - Family goal setting

45 CFR 1304.40(a)(I) - Grantee and delegate agencies must engage in a process of collaborative partnership building with parents to establish mutual trust and to identify family goals, strengths, and necessary services and other supports. This process must be initiated as early after enrollment as possible and it must take into consideration each family's readiness and willingness to participate in the process.

45 CFR 1304.40(a)(2) - As part of this ongoing partnership, grantee and delegate agencies must offer parents opportunities to develop and implement individualized family partnership agreements that describe family goals, responsibilities, timetables and strategies for achieving these goals as well as progress in achieving them. In home-based program options, this agreement must include the above information as well as the specific roles of parents in home visits and group socialization activities (see 45 CFR 1306.33(b)).

45 CFR 1304.40(a)(3) - To avoid duplication of effort, or conflict with, any preexisting family plans developed between other programs and the Early Head Start or Head Start family, the family partnership agreement must take into account, and build upon as appropriate, information obtained from the family and other community agencies concerning preexisting family plans. Grantee and delegate agencies must coordinate, to the extent possible, with families and other agencies to support the accomplishment of goals in the preexisting plans. 45 CFR 1304.40(a)(4) - A variety of opportunities must be created by grantee and delegate agencies for interaction with parents throughout the year. 
45 CFR 1304.4O(a)(5) - Meetings and interactions with families must be respectful of each family's diversity and cultural and ethnic background

45 CFR 1304.40(b) - Accessing community services and resources

45 CFR 1304.40(b)(l) - Grantee and delegate agencies must work collaboratively with all participating parents to identify and continually access, either directly or through referrals, services and resources that are responsive to each family's interests and goals, including:

45 CFR 1304.40(b)(I)(i) - Emergency or crisis assistance in areas such as food, housing, clothing, and transportation;

45 CFR 1304.40(b)(I)(ii) - Education and other appropriate interventions, including opportunities for parents to participate in counseling programs or to receive information on mental health issues that place families at risk, such as substance abuse, child abuse and neglect, and domestic violence; and

45 CFR 1304.40(b)(I)(iii) - Opportunities for continuing education and employment training and other employment services through formal and informal networks in the community.

45 CFR 1304.40(b)(2) - Grantee and delegate agencies must follow-up with each family to determine whether the kind, quality, and timeliness of the services received through referrals met the families expectations and circumstances.

45 CFR 1304.4O(c) - Services to pregnant women who are enrolled in programs serving pregnant women, infants, and toddlers

45 CFR 1304.4O(c)(I) - Early Head Start grantee and delegate agencies must assist pregnant women to access comprehensive prenatal and postpartum care, through referrals, immediately after enrollment in the program. This care must include: 
45 CFR 1304.40(c)(I)(i) - Early and continuing risk assessments, which include an assessment of nutritional status as well as nutrition counseling and food assistance, if necessary;

45 CFR 1304.40(c)(I)(ii) - Health promotion and treatment, including medical and dental examinations on a schedule deemed appropriate by the attending health care providers as early in the pregnancy as possible; and

45 CFR 1304.40(c)(I)(iii) - Mental health interventions and follow-up, including substance abuse prevention and treatment services, as needed.

45 CFR 1304.40(c)(2) - Grantee and delegate agencies must provide pregnant women and other family members, as appropriate, with prenatal education on fetal development (including risks from smoking and alcohol), labor and delivery, and post-partum recovery (including maternal depression).

45 CFR 1304.40(c)(3) - Grantee and delegate agencies must provide information on the benefits of breast feeding to all pregnant and nursing mothers. For those who choose to breast feed in center-based programs, arrangements must be provided as necessary.

45 CFR 1304.40(d) -Parent involvement - general

45 CFR 1304.40(d)(I) -In addition to involving parents in program policy-making and operations (see 45 CFR 1304.50), grantee and delegate agencies must provide parent involvement and education activities that are responsive to the ongoing and expressed needs of the parents, both as individuals and as members of a group. Other community agencies should be encouraged to assist in the planning and implementation of such programs.

45 CFR 1304.40(d)(2) - Early Head Start and Head Start settings must be open to parents during all program hours. Parents must be welcomed as visitors and encouraged to observe children as often as possible and to participate with children in group activities. The 
participation of parents in any program activity must be voluntary, and must not be required as a condition of the child's enrollment.

45 CFR 1304.40(d)(3) - Grantee and delegate agencies must provide parents with opportunities to participate in the program as employees or volunteers (see 45 CFR 1304.52(b)(3) for additional requirements about hiring parents).

45 CFR 1304.40(e) -Parent involvement in child development and education 45 CFR 1304.40(e)(I) - Grantee and delegate agencies must provide opportunities to include parents in the development of the programs curriculum and approach to child development and education (see 45 CFR 1304.3(a)(5) for a definition of curriculum).

45 CFR 1304.40(e)(2) - Grantee and delegate agencies operating home-based program options must build upon the principles of adult learning to assist, encourage, and support parents as they foster the growth and development of their children.

45 CFR 1304.40(e)(3) - Grantee and delegate agencies must provide opportunities for parents to enhance their parenting skills, knowledge, and understanding of the educational and developmental needs and activities of their children and to share concerns about their children with program staff (see 45 CFR 1304.21) for additional requirements related to parent involvement).

45 CFR 1304.40(e)(4) - Grantee and delegate agencies must provide, either directly or through referrals to other local agencies, opportunities for children and families to participate in family literacy services by:

45 CFR 1304.40(e)(4)(i) - Increasing family access to materials, services, and activities essential to family literacy development; and 45 CFR 1304.40(e)(4)(ii) - Assisting parents as adult learners to recognize and address their 
own literacy goals.

45 CFR 1304.40(e)(5) - In addition to the two home visits, teachers in center-based programs must conduct staff-parent conferences, as needed, but no less than two per program year, to enhance the knowledge and understanding of both staff and parents of the educational and developmental progress and activities of children in the program (see 45 CFR 1304.2 I (a)(2)(iii) and 45 CFR 1304.40(i) for additional requirements about staff-parent conferences and home visits).

45 CFR 1304.40(1) - Parent involvement in health, nutrition, and mental health education 45 CFR 1304.40(1)(1) - Grantee and delegate agencies must provide medical, dental, nutrition, and mental health education programs for program staff, parents, and families.

45 CFR 1304.40(1)(2) - Grantee and delegate agencies must ensure that, at a minimum, the medical and dental health education program:

45 CFR 1304.40(1)(2)(i) - Assists parents in understanding how to enroll and participate in a system of ongoing family health care;

45 CFR 1304.40(1)(2)(ii) - Encourages parents to become active partners in their children's medical and dental health care process and to accompany their child to medical and dental examinations and appointments; and

45 CFR 1304.40(f)(2)(iii) - Provides parents with the opportunity to learn the principles of preventive medical and dental health, emergency first-aid, occupational and environmental hazards, and safety practices for use in the classroom and in the home. In addition to information on general topics (e.g., maternal and child health and the prevention of Sudden Infant Death Syndrome), information specific to health needs of individual children must also be made available to the extent possible. 
45 CFR 1304.40(f)(3) - Grantee and delegate agencies must ensure that the nutrition education program includes, at a minimum:

45 CFR 1304.40(f)(3)(i) - Nutrition education in the selection and preparation of foods to meet family needs and in the management of food budgets; and

45 CFR 1304.40(f)(3)(ii) - Parent discussions with program staff about the nutritional status of their child.

45 CFR 1304.40(f)(4) - Grantee and delegate agencies must ensure that the mental health education program provides, at a minimum (see 45 CFR 1304.24 for issues related to mental health education):

45 CFR 1304.40(f)(4)(i) - A variety of group opportunities for parents and program staff to identify and discuss issues related to child mental health;

45 CFR 1304.40(f)(4)(ii) - Individual opportunities for parents to discuss mental health issues related to their child and family with program staff; and

45 CFR 1304.40(f)(4)(iii) - The active involvement of parents in planning and implementing any mental health interventions for their children.

45 CFR 1304.4O(g) - Parent involvement in community advocacy

45 CFR 1304.40(g)(I) - Grantee and delegate agencies must:

45 CFR 1304.40(g)(I)(i) - Support and encourage parents to influence the character and goals of community services in order to make them more responsive to their interests and needs; and

45 CFR 1304.40(g)(I)(ii) - Establish procedures to provide families with comprehensive information about community resources (see 45 CFR 1304.41 (a)(2) for additional requirements). 
45 CFR 1304.40(g)(2) - Parents must be provided regular opportunities to work together, and with other community members, on activities that they have helped develop and in which they have expressed an interest.

45 CFR 1304.40(h) - Parent involvement in transition activities

45 CFR 1304.40(h)(I) - Grantee and delegate agencies must assist parents in becoming their children's advocate as they transition both into Early Head Start or Head Start from the home or other child care setting, and from Head Start to elementary school, a Title I of the Elementary and Secondary Education Act preschool program, or a child care setting.

45 CFR 1304.40(h)(2) - Staff must work to prepare parents to become their children's advocate through transition periods by providing that, at a minimum, a staff-parent meeting is held toward the end of the child's participation in the program to enable parents to understand the child's progress while enrolled in Early Head Start or Head Start.

45 CFR 1304.40(h)(3) - To promote the continued involvement of Head Start parents in the education and development of their children upon transition to school, grantee and delegate agencies must:

45 CFR 1304.40(h)(3)(i) - Provide education and training to parents to prepare them to exercise their rights and responsibilities concerning the education of their children in the school setting; and

45 CFR 1304.40(h)(3)(ii) - Assist parents to communicate with teachers and other school personnel so that parents can participate in decisions related to their children's education. 45 CFR 1304.40(h)(4) - See 45 CFR 1304.41(c) for additional standards related to children's transition to and from Early Head Start or Head Start. 
45 CFR 1304.4O(i) - Parent involvement in home visits

45 CFR 1304.40(i)(I) - Grantee and delegate agencies must not require that parents permit home visits as a condition of the child's participation in Early Head Start or Head Start center-based program options. Every effort must be made to explain the advantages of home visits to the parents.

45 CFR 1304.40(i)(2) - The child's teacher in center-based programs must make no less than two home visits per program year to the home of each enrolled child, unless the parents expressly forbid such visits, in accordance with the requirements of 45 CFR 1306.32(b)(8). Other staff working with the family must make or join home visits, as appropriate.

45 CFR 1304.40(i)(3) - Grantee and delegate agencies must schedule home visits at times that are mutually convenient for the parents or primary caregivers and staff.

45 CFR 1304.40(i)(4) - In cases where parents whose children are enrolled in the center-based program option ask that the home visits be conducted outside the home, or in cases where a visit to the home presents significant safety hazards for staff, the home visit may take place at an Early Head Start or Head Start site or at another safe location that affords privacy. Home visits in home-based program options must be conducted in the family's home. (See 45 CFR 1306.33 regarding the home-based program option.)

45 CFR 1304.40(i)(5) - In addition, grantee and delegate agencies operating home-based program options must meet the requirements of 45 CFR 1306.33(a)(I) regarding home visits.

45 CFR 1304.40(i)(6) - Grantee and delegate agencies serving infants and toddlers must arrange for health staff to visit each newborn within two weeks after the infants birth to ensure the well-being of both the mother and the child. 
45 CFR 1304.41- Community Partnerships

45 CFR 1304.41(a) -Partnerships

45 CFR 1304.41 (a)(I) - Grantee and delegate agencies must take an active role in community planning to encourage strong communication, cooperation, and the sharing of information among agencies and their community partners and to improve the delivery of community services to children and families in accordance with the agency's confidentiality policies. Documentation must be maintained to reflect the level of effort undertaken to establish community partnerships (see 45 CFR 1304.51 for additional planning requirements).

45 CFR 1304.41(a)(2) - Grantee and delegate agencies must take affirmative steps to establish ongoing collaborative relationships with community organizations to promote the access of children and families to community services that are responsive to their needs, and to ensure that Early Head Start and Head Start programs respond to community needs, including:

45 CFR 1304.41 (a)(2)(i) - Health care providers, such as clinics, physicians, dentists, and other health professionals;

45 CFR 1304.41 (a)(2)(ii) - Mental health providers;

45 CFR 1304.41 (a)(2)(iii) - Nutritional service providers;

45 CFR 1304.41(a)(2)(iv) - Individuals and agencies that provide services to children with disabilities and their families (see 45 CFR 1308.4 for specific service requirements); 45 CFR 1304.41(a)(2)(v) - Family preservation and support services;

45 CFR 1304.41 (a)(2)(vi) - Child protective services and any other agency to which child abuse must be reported under State or Tribal law;

45 CFR 1304.41(a)(2)(vii) - Local elementary schools and other educational and cultural institutions, such as libraries and museums, for both children and families; 
45 CFR 1304.41(a)(2)(viii) - Providers of child care services; and

45 CFR 1304.41(a)(2)(ix) - Any other organizations or businesses that may provide support and resources to families.

45CFR Part 1304 Performance Standards for Operation of Head Start Programs 
Appendix C

Cover Letter for Survey 


\section{Department of Curriculum \& Instruction/Literacy Studies \\ WestVirginiaUniversity. \\ College of Human Resources and Education}

Dear Participant,

This letter is a request for you to take part in a research project to assess factors related to parental involvement in early literacy skills in Head Start in West Virginia at WVU. This project is being conducted by Arlene Clausell, MA in Curriculum and Instruction at WVU with supervision of Dr. Joy Saab, an associate professor in the College of Human Resources and Education, for a Doctorate Degree in Curriculum and Instruction. Your participation in this project is greatly appreciated and will take approximately 10 minutes to fill out the attached questionnaire.

Your involvement in this project will be kept as confidential as legally possible. All data will be reported in the aggregate. You must be 18 years of age or older to participate. I will not ask any information that should lead back to your identity as a participant. Your participation is completely voluntary. You may skip any question that you do not wish to answer and you may discontinue at any time.. West Virginia's University's Institutional Review Board acknowledgement of this project is on file.

I hope that you will participate in this research project, as it could be beneficial in understanding the impact of grades on student life. Thank you very much for your time. Should you have any questions about this letter or the research project, please feel free to contact Arlene Midget Clausell at (304)-599-5855) or by e-mail at aclausel@mix.wvu.edu and Dr. Joy Faini Saab at Joy.Saab@Mail.wvu.edu.

Thank you for your time and help with this project.

Sincerely,

Arlene Midget Clausell MA

Joy Faini Saab EdD 
Appendix D

Cover Letter for Focus Group 


\section{Department of Curriculum \& Instruction/Literacy Studies \\ WestVirginiaUniversity. \\ College of Human Resources and Education}

Dear Participant,

This letter is a request for you to take part in a research project to examine the issues related to parents involvement in their preschoolers' early literacy skills. This research is being conducted by Arlene Midget Clausell, MA a doctoral student in curriculum and instruction at WVU under the supervision of Dr. Joy Faini Saab, EdD an Associate Professor College of Human Resources, for a Doctoral Degree in Education. Your participation in this project is voluntary, greatly appreciated and will take approximately 60 minutes in a focus group discussion about issues of parental involvement in teaching early literacy skills. The session will be audiotape recorded. The tape will be destroyed as soon as all of information has been written down. I will keep the data confidential, but I cannot promise that any other participant in the group will.

Your involvement in this project will be kept as confidential as legally possible. All data will be reported in the aggregate. You must be 18 years of age or older to participate. I will not ask any information that should lead back to your identity as a participant. Your participation is completely voluntary. You may skip any question that you do not wish to answer and you may discontinue at any time. The West Virginia University Institutional Review Board (IRB) has acknowledgement of this study on file.

I hope that you will participate in this research project, as it could be beneficial in understanding the impact of parental involvement in teaching children early literacy skills. Thank you very much for your time. Should you have any questions about this letter or the research project, please feel free to contact Arlene Clausell at (304 599-5855) or by e-mail at aclausel@mix.wvu.edu and Dr. Joy Faini Saab at 304-293-4385 or by e-mail at Joy.Saab@mail.wvu.edu.

Thank you for your time and help with this project.

Sincerely,

Arlene Midget Clausell, MA

Joy Faini Saab, Ed.D. 


\title{
CURRICULUM VITA
}

\author{
ARLENE M. CLAUSELL \\ ONE CATALPA STREET \\ MORGANTOWN, WV 26505
}

(304) 599-5855

E-MAIL: $\underline{\text { read_specialist@hotmail.com }}$

\section{EDUCATION}

2010 EdD

2009 Passed Oral Defense for Dissertation Nov. 2009

2008 Candidate for Doctorate in Education

Completed course work and passed Comprehensive Exams

For Curriculum and Instruction Major and Reading Minor

Doctoral Degree

West Virginia University

Morgantown, WV

2002 Participant in Project Lead State Leadership Training Program

1980 Marshall University

Huntington, WV

Major: Career Education

1980 Completed a series of courses in career education

1973 West Virginia University

Morgantown, WV

MA in Reading

1968 West Virginia State University

Institute, WV

BS, Elementary Education 


\section{RECENT COURSES}

2009 International Writing Center Seminar July 11-17, 2009, Temple University, Philadelphia, $\mathrm{Pa}$

2009 Martin Luther King Study Tour

2005 Summer Study Abroad: Reggio Emillia, Italy Early Childhood Program

2003 Adtp: Implementing Reading Assistance 2- WVU

2003 Instructional Design

2002 Project Leadership - W V State Board of Education

2002 Technology Advanced Standards - EdVenture/Monongalia County Schools

$2001 \quad$ Introduction to Technology - WVU

\section{PROFESSIONAL QUALIFICATIONS}

Professional Administrative Certificate Specializations:

- Principal- Elem/Jr Hi, Major 1-9

- Principal- Mid/Jr Hi/Senior High, Major 5 - 12

- Superintendent- Major K - 12

- Supervisor- General Instruction, Major K - 12

- Vocational Administration- Major 5 - 12

- Elementary Education Teacher- Major 1 - 8

- English Social Studies Teacher- Major 1 - 9

- Reading Specialist- Major K - 12

1993 Fellow - WV Writing Project

1995 Fellow - WV Writing Project, Advanced

\section{Awards, Fellowships}

2001 WNPB-TV, "Reader" for First Book Early Literacy Project

2000 Ruby Memorial Hospital Friends Volunteer Organization

- Volunteer of the Month - August

1998 Ashland Oil Golden Apple Achiever Award

1997 National Writing Project Award

- First Place for Project: A Picture is Worth a Thousand Words

1997 Received All American Scholar Award

- Monongalia County Schools Off Your Seat, On Your Feet Campaign

1997 Received Award For Chairperson of Cass Elementary

- School Campaign WV English/Language Arts Council

1997 Received Esteemed Colleague Award for Outstanding Service

- National Council of Teachers of English, Chicago, IL

1996 Received the Affiliate Multicultural Award for Best Multicultural Program 
1996 Received the "Teachers For The Dream" Affiliate Award

\section{TEACHING EXPERIENCE}

WEST VIRGINIA UNIVERSITY

2007 Visiting Professor Children's Literature

2008 Visiting Professor Children's Literature

2003 Reading Clinic Teaching Assistant

Monongalia County Board of Education

2001 Easton Elementary School

2004 - Reading Specialist, Title 1

2001 Arnettsville Elementary School

- Reading Specialist, Title 1

1999 Brookhaven Elementary School

2001 - Reading Specialist, Title 1

1998 Central/Arnettsville Elementary Schools

1999 - Reading Specialist, Title 1

1997 Cool Springs Elementary School

1998 - Reading Specialist, Title 1

1995 Cass Elementary School

- Reading Specialist, Title 1

1997 - Building Level Attendance Coordinator (1996-1997)

1994 Mason-Dixon Elementary School

1995 - Reading Specialist, Title 1

1987 North Elementary School

- 1st Grade Teacher 1987-89

1984 Mt. Pleasant Elementary School

1987 - 2nd Grade Teacher

1981 First Ward Elementary School

1984 - 4th Grade Teacher

1980 Woodburn/Jerome Park Elementary School

1981 - Reading Specialist, Chapter 1

1974 Cass Elementary School

- $\quad$ - 5th Grade Teacher

1979 - Teacher in Charge 1977 - 1979

Hancock County Board of Education

1969- Cove Elementary School 
1974 - 4th Grade Teacher

Steubenville, Ohio Public School District

1969 Grant Elementary/Junior High School

- $\quad-\quad$ Remedial Language Arts Teacher 7th \& 8th Grade

1969 - Substitute Teacher

Hancock County Board of Education

1968 - Cove Elementary School

1968 - Substitute Teacher

West Virginia State Committee

Serve d Committee for Training County Board of Education members

West Virginia State Board of Education

West Virginia University Committees

2008 - Student Advisory Board for Human Resources and Education 2008

09

Present

2005- Dr. Martin Luther King Jr. Program Committee

10 


\section{MONONGALIA COUNTY SCHOOLS COUNCILS/COMMITTEES}

1984 Monongalia County Public Schools K - 4 Curriculum Committee

1988

1982 Chapter 2 Innovative Grants Committee

1982 English Textbook Adoption Committee

1980 Monongalia County Public School Curriculum Council for Language Arts $-$

1984

\section{PRESENTATIONS}

2006 West Virginia State Reading Conference, Greenbrier Resort, WV

Parent Involvement and How It Fits with the Reggio Emillia Approach to Learning “

The WVU Minority Graduate Student Research and Mentoring Exchange Morgantown WV

Presented "African American Children and Success in School

National Council of Teachers of English

2000 National Conference, Milwaukee, WI

Discussant Leader for Elementary Section Round-UP

Panel Discussant on Positive Parent Involvement

1999 National Conference, Denver Co-"Child Chats"

1998 National Conference, Nashville, TN

Chaired Presentation - Native Language

1997 National Conference, Detroit, MI

'Teachers For The Dream' Workshop

\section{Chaired Affiliate Round Table Discussion Group}

2000 National Science Teachers Association

Regional Conference, Pittsburgh, PA

"Water Quality" at Rock Camp Shar-a-thon

Geological Survey, WV Department of Education, National Science Foundation " 
Morgantown, WV --Presentation on "Water Quality

West Virginia Science Teachers Association- Morgantown. WV

Shar-a-thon: The Importance of Water Quality Testing"

\section{PUBLICATIONS}

2000 NCTE Teacher 2000 Project

Cyber Brief - Internet Article: Positive Parent Involvement

1999 K-12 Magazine-Article "Child Chats"

\section{WORKSHOPS}

2000 Co-Chair, WVELAC Regional Workshop for Elementary Teachers

West Liberty State College, West Liberty, WV

1998 WV Center of Professional Development, Governor's Summer Institute, Westover Facilitator

1998 Mason Dixon Elementary School, WV Geological Survey, WV Department of Education, National Science Foundation Conducted Workshop on Mine Subsidence

1997 West Virginia Reading Association Leadership Conference Workshop

1999, WV Center for Professional Development, Governor's Summer Institute, 1996 Fairmont, Facilitator

1997 Monongalia County Schools- Math, A Way of Thinking

1996 Appalachia Culture and Texture Institute, Fairmont State College

1996 WV Geological Survey, WV Department of Education, National Science Foundation Teacher Enhancement Course: Earth Science in WV for the $21^{\text {st }}$ Century, Rock Camp 2

Monongalia County Schools, Title 1

Learn at the Lake Language Arts Retreat, II

Learn at the Lake Language Arts Retreat

Summer Summit 4

Summer Summit 3

Summer Summit 1

1994

WV Geological Survey, WV Department of Education, National Science Foundation 
Teacher Enhancement Course: Earth Science in WV for the $21^{\text {st }}$ Century, Rock Camp I

1992

Summer Institute for West Virginia Teachers

$1991-92$

Monongahela Power Co. Educators' Energy Workshop

2000

Morgantown Energy Technology Center

Hands-On Elementary Teachers Science Training

Workshop

1990

NASA Training Center, Wheeling Jesuit College

NASA Workshop for Teachers

\section{PROFESSIONAL ORGANIZATIONS}

2009-10 International Writing Center Organization

2004-10 American Education Research Association

2006-10 Morgantown Toastmasters International Clubs

2009-10 Vice President of Education

2008-09 Secretary

2003-04 National Association of Elementary Principals

2000-10 National Association of the Education of Young Children

2000-10 Southern Early Childhood Association

2000-10 West Virginia Early Childhood Association

1999-11 Phi Delta Kappa National Honorary

2009-00 Present Treasurer West Virginia University Chapter

Treasurer

2005

Attended National Phi Delta Kappa Conferences Washington,

$2006 \quad D C$

1966-10

Las Vegas, Nevada

National Education Association

1969-

West Virginia Education Association

2001

2003

Delegate Assembly Representative

$1980 \quad$ Minority Leadership Conference

1974 Delegate, Monongalia County 
Delegate, Hancock County

1974-10 $1986 \& 03$

2004

1980-10 2009

1992

1983

1993-10

1993-10

2002-04

1999-04

1999-01

1999-01

1999-00

1999-01

1999-00

2000-03

2000-01

1999-01

1996

1994

2008

2005

2004

2001

\section{Monongalia County Education Association}

School Representative

Secretary for County Organization

International Reading Association

Attended International Conference in Minneapolis,Minnesota

Attended World Conference, Maui, Hawaii Attended Regional

Conference, Baltimore, $M D$

West Virginia Reading Association

National Council of Teachers of English

Standing Committee for Testing and Assessment

Subcommittees

Headquarters; Advocacy \& Diversity; New Initiatives, Member

Benefits \& Affiliate Concerns, Technology Concerns

Committees

Member of Executive Committee

Elementary Steering Committee

Liaison to:

Commission on Language, Early Childhood Issue

Storytelling Committee

Title 1 Committee

People of Color Workshop

Member of Search Committee for Executive Director

Elected National Elementary Representative-at-Large

WVELAC Representative,

Regional Leadership Meeting, Pittsburgh, PA

Regional Meeting, Baltimore, MD

Minority Leadership Standards Workshop

WVELAC State Minority Representative

NCTE Conferences Attended

National Conference, San Francisco, Ca.

National Conference, Pittsburgh, PA

National Conference, Indianapolis, IN

National Conference, Baltimore, MD 


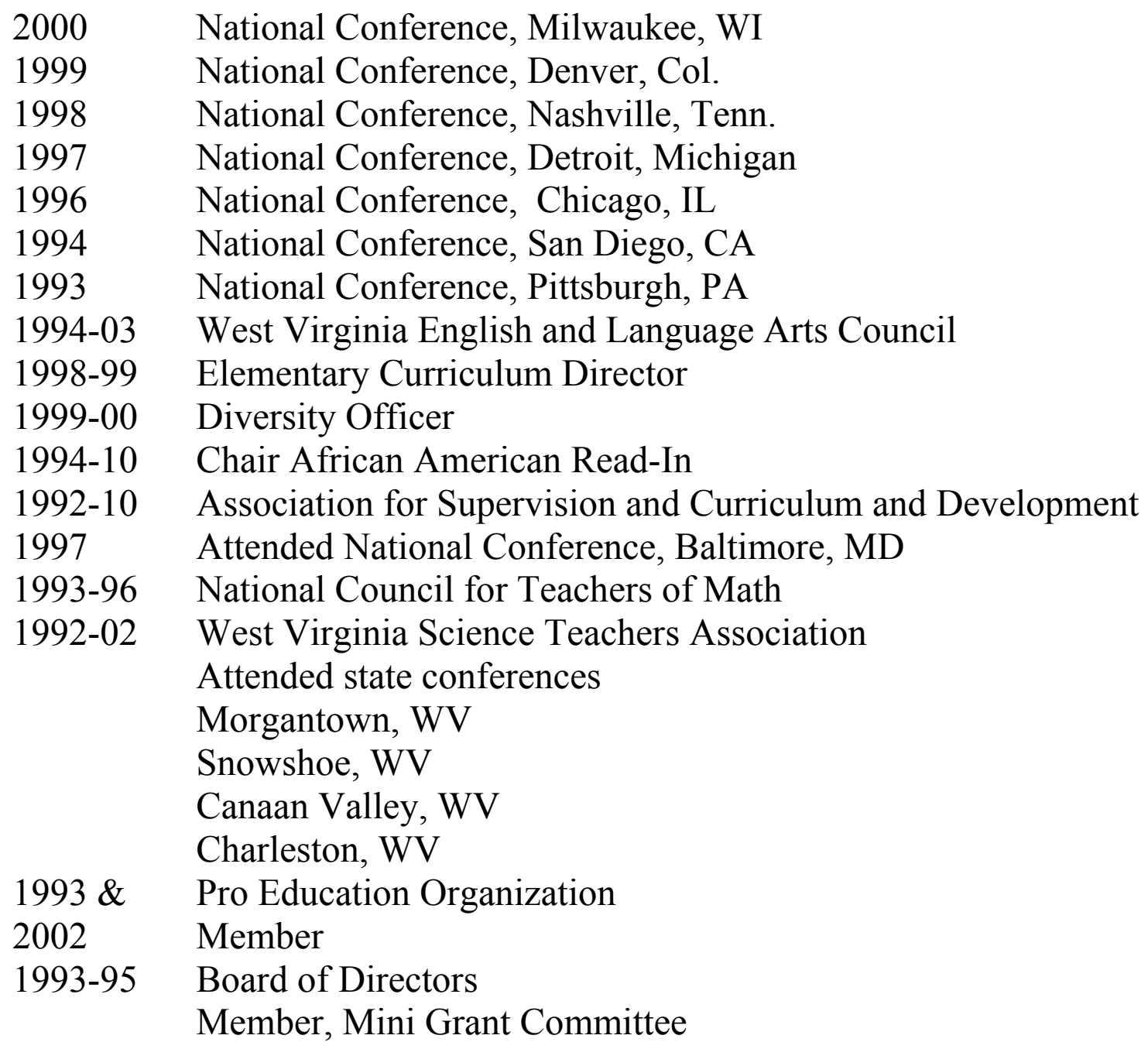

\section{COMMUNITY SERVICE ACTIVITIES}

1985-10 West Virginia State Medical Alliance, member

2000-05 Liaison to WVU Medical Student Spouses

1996 Confluence Leadership Training by American Medical Alliance, Chicago, IL

199-97 State Health Projects Chair

1997-99 Regional Director, Monongalia County \& Eastern Panhandle Alliances

1985-09 Monongalia County Medical Alliance

1998-09 AMA-ERF Foundation Chair

Chair, Fundraising

1993-07 Monongalia County Medical Alliance

Newsletter Editor 
Governing Board Member

Chair, Health Projects

Domestic Violence Month Activity

Save-A-Shelter Bag for RDVIC

Annual Purchase and Distribution of Anti-Violence Information to all

Kindergarten - Third Grade Students (Mon. County)

Developed and distributed Informational Attendance Form to all Monongalia County school students in grades Head Start $-5^{\text {th }}$.

1976-10 Friends of Ruby Memorial Hospital (Volunteer Organization)

1996 Became Life Member

1976-98 Mt. Hermon Baptist Church, Morgantown WV

1993-97 Sunday School Teacher

Youth Supervisor

1985-98 Youghiogheny Western Baptist Association, Uniontown PA

1997-98 Regional Youth Assistant Supervisor

1996-99 Regional Youth Supervisor

1998-09 Morning Star Baptist Church, Fairmont, WV

1998-09 Sunday School Teacher

1996-03 Monongalia/Preston Counties United Way, Morgantown, WV Member, Review Committees for RDVIC, PATCH, Mental Health Association, and Bridges.

1985-04 Member, Boy Scouts of America Troop Committee Member, Boy Scout Troop 44, Morgantown. WV

2000-09 American Cancer Society

2000-09 Relay for Life Volunteer

2003-05 Chair for Same Day Volunteers 